\title{
The Development of Third-Generation Tetracycline Antibiotics and New Perspectives
}

\author{
Aura Rusu * and Emanuela Lorena Buta
}

Citation: Rusu, A.; Buta, E.L. The Development of Third-Generation Tetracycline Antibiotics and New Perspectives. Pharmaceutics 2021, 13, 2085. https://doi.org/10.3390/ pharmaceutics 13122085

Academic Editor: Teresa Cerchiara

Received: 29 October 2021

Accepted: 3 December 2021

Published: 5 December 2021

Publisher's Note: MDPI stays neutral with regard to jurisdictional claims in published maps and institutional affiliations.

Copyright: (c) 2021 by the authors. Licensee MDPI, Basel, Switzerland. This article is an open access article distributed under the terms and conditions of the Creative Commons Attribution (CC BY) license (https:/ / creativecommons.org/licenses/by/ $4.0 /)$.
Pharmaceutical and Therapeutical Chemistry Department, Faculty of Pharmacy, George Emil Palade University of Medicine, Pharmacy, Science and Technology of Targu Mures, 540142 Targu Mures, Romania; lorrenush@yahoo.com

* Correspondence: aura.rusu@umfst.ro; Tel.: +40-766-600-898

\begin{abstract}
The tetracycline antibiotic class has acquired new valuable members due to the optimisation of the chemical structure. The first modern tetracycline introduced into therapy was tigecycline, followed by omadacycline, eravacycline, and sarecycline (the third generation). Structural and physicochemical key elements which led to the discovery of modern tetracyclines are approached. Thus, several chemical subgroups are distinguished, such as glycylcyclines, aminomethylcyclines, and fluorocyclines, which have excellent development potential. The antibacterial spectrum comprises several resistant bacteria, including those resistant to old tetracyclines. Sarecycline, a narrow-spectrum tetracycline, is notable for being very effective against Cutinebacterium acnes. The mechanism of antibacterial action from the perspective of the new compound is approached. Several severe bacterial infections are treated with tigecycline, omadacycline, and eravacycline (with parenteral or oral formulations). In addition, sarecycline is very useful in treating acne vulgaris. Tetracyclines also have other non-antibiotic properties that require in-depth studies, such as the anti-inflammatory effect effect of sarecycline. The main side effects of modern tetracyclines are described in accordance with published clinical studies. Undoubtedly, this class of antibiotics continues to arouse the interest of researchers. As a result, new derivatives are developed and studied primarily for the antibiotic effect and other biological effects.
\end{abstract}

Keywords: tetracyclines; structure-activity relationship; mechanism; antibacterial activity; resistance; fluorocycline; aminomethylcycline; glycylcycline

\section{Introduction}

Tetracyclines are an important class of broad-spectrum antibiotics that prevent bacterial growth by inhibiting protein biosynthesis. This large family includes compounds with bacteriostatic activity and a wide range of uses, from Gram-positive and Gram-negative bacterial infections to those caused by a protozoan parasite and intracellular organisms [1]. Sarecycline is unique, being the only narrow-spectrum antibiotic in the tetracycline-class family. The basic structure of tetracyclines consists of four linearly condensed benzene rings in a hydronaphtacene nucleus. The essential differences between the analogues of this class are given by the C5, C6, C7, and C9 substituents (Figure 1) [2].

\subsection{Brief History of Tetracycline Antibiotics}

The emergence of tetracycline development is due to the contribution of hundreds of dedicated researchers, scientists, and clinicians over more than 60 years [3]. Since their discovery (1948, aureomycin), tetracyclines have played an essential role in treating bacterial infections [4]. Stimulated by the extraordinary success of penicillins, several companies and academic institutions have focused on discovering new antibiotics produced by microorganisms, analysing numerous samples of soil sent from different parts of the world. It was observed that actinomycete bacteria produced a yellow colony, with a remarkable inhibitory effect against many pathogenic strains, including rickettsia and Gram-positive 
and Gram-negative bacteria. This actinomycete bacteria became famous for its broadspectrum antibiotic. The first tetracycline was extracted from Streptomyces aureofaciens and was named aureomycin (syn. chlortetracycline) [5-8]. Professor Benjamin Minge Duggar supervised the discovery of the first tetracycline. After the Food and Drug Administration (FDA) approval in 1948, aureomycin saved many lives and brought fame and profit to the Cyanamid (Lederle Laboratories Division) manufacturing company, being successfully marketed $[3,7,9,10]$. After Pfizer isolated Streptomyces rimosus, the aureomycin and terramycin (syn. oxytetracycline) were discovered [7]. This new compound was the second representative of this class of antibiotics, similar in chemical structure but with superior bioavailability and water solubility. The FDA approved Terramycin in $1950[3,9,11]$.

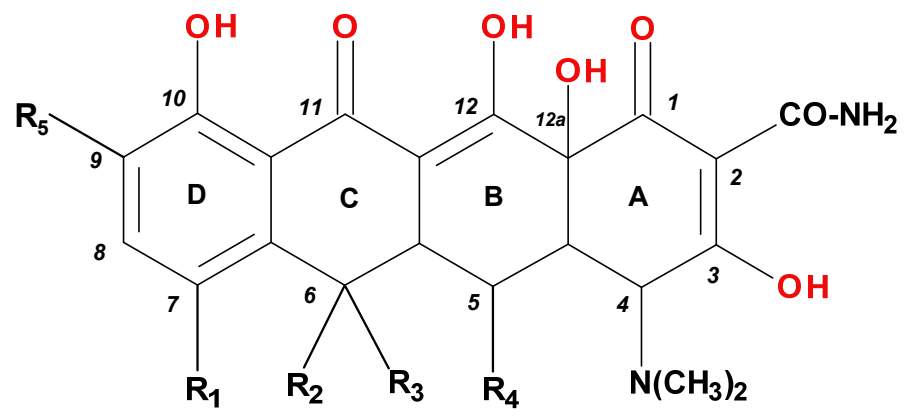

Figure 1. Tetracyclines-the general chemical structure and conventional numbering of the condensed rings and key positions.

Tetracycline was discovered in 1953, on the basis of the chemical structure of chlortetracycline, by catalitic hidrogenation (with palladium and hydrogen). The new antibiotic agent presented and improved the pharmacokinetic profile, which quickly became a favourite in therapy $[12,13]$. This remarkable success has proven for the first time in history that other biologically active and valuable antibiotics can be obtained by operating changes on the basic structure (molecule optimisations) $[3,14]$. After discovering chlortetracycline, oxytetracycline, and tetracycline (first generation of tetracyclines), the chemists of Pfizer and Lederle Laboratories began the development of new tetracyclines, with superior pharmacokinetic properties, wider antimicrobial spectrum, and lower toxicity [15]. Among the discovered representatives were methacycline (1966), doxycycline (1967), and minocycline $(1972)[13,16]$. Doxycycline is a semisynthetic analogue based on the chemical structure of the metacycline, approved in 1967 by the FDA. These tetracyclines are classified in the second generation (Table S1—Supplementary Materials) [3,14,17].

The further development of semisynthetic analogues of the second generation, and, more recently, of the third generation (Table 1), reveals the evolution of this class. The modern tetracyclines had acquired high potency and an increased efficacy, even against bacteria resistant to tetracyclines [18-20]. Therefore, biochemical mutants of Streptomycetes strains have been created for a higher production yield and to discover novel tetracyclines $[3,15]$.

Table 1. Tetracyclines—classification into generations [14,21-24].

\begin{tabular}{|c|c|c|}
\hline Generations & Obtaining Method & Representatives \\
\hline First & Biosynthesis & $\begin{array}{c}\text { Chlortetracycline, oxytetracycline, tetracycline, } \\
\text { demeclocycline }\end{array}$ \\
\hline Second & Semisynthesis & $\begin{array}{l}\text { Doxycycline, minocycline, lymecycline, } \\
\text { meclocycline, methacycline, rolitetracycline }\end{array}$ \\
\hline Third & $\begin{array}{l}\text { Semisynthesis } \\
\text { Total synthesis }\end{array}$ & $\begin{array}{c}\text { Tigecycline, omadacycline, sarecycline } \\
\text { Eravacycline }\end{array}$ \\
\hline
\end{tabular}

Therefore, compounds such as demeclocycline were discovered, being later converted in 1971 to a C7-amino-derivative known as minocycline. Some authors classified minocy- 
cline as the last tetracycline in the second generation. Moreover, demeclocycline was a precursor of sancycline (obtained by reduction), a tetracycline with a simplified chemical structure and retained biological activity [1,25]. Thus, the main advantage of minocycline is a broader spectrum of activity compared to previously representatives. Furthermore, minocycline presented a better pharmacokinetic profile and was the most potent representative at the time, being the last introduced on the market in the next three decades $[3,17,26]$.

\subsection{The Discovery of Modern Tetracyclines}

The growing occurrence of bacterial resistance to antibiotics has once again aroused the interest of scientists in the development of new tetracyclines. Thus, at the end of the 1980s, the programs were reopened for the synthesis of new compounds that could be classified into a new generation (the third one), re-evaluating the compounds already synthesised (Table S2-Supplementary Materials) [3]. The main interest was about the modification of C7 and C9 positions of the D ring in the sancycline structure (Figure 2, Table S3-Supplementary Materials). These steps have led to the discovery of a novel class of C9-aminotetracyclines, which bear a glycyl moiety known as glycylcycline [3,27-29].

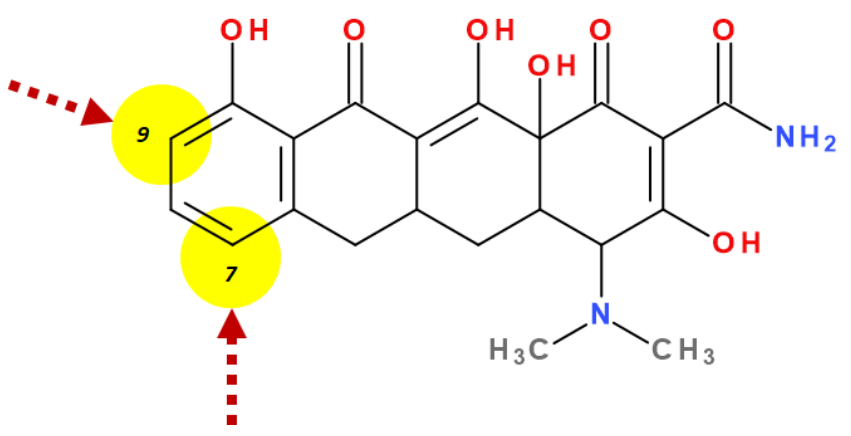

Figure 2. The chemical structures of sancycline; key positions highlighted C7 and C9 for structural design optimisation to obtain new derivatives.

Modern tetracyclines include derivatives with more or less similar chemical structures: a glycylglicine (tigecycline), an aminomethylcycline (omadacycline), a fluorocycline (eravacycline), and a 7-[(methoxy-(methyl)-amino)-methyl]methyl] derivative (sarecycline) (Figure 3).

Tigecycline is a synthetic derivative of minocycline discovered in 1993. Tigecycline was the first tetracycline introduced in therapy after more than 30 years. Thus, tigecycline could be considered the prototype of a new subclass of tetracyclines [27,29]. This new tetracycline has the advantage of a superior potency over Gram-positive and Gram-negative multidrug-resistant bacteria (multiple drug resistance, MDR) [26,30]. Tigecycline was discovered by Wyeth Pharmaceuticals Inc. and approved by the FDA in 2005 [31] and later by the European Medicine Agency (EMA) in 2006, under the trade name Tygacil [32]. Tygacil received approval for complicated intra-abdominal and complicated skin and soft tissue infections [33,34]. Likewise, in 2008, the FDA approved the use of tigecycline to treat community-acquired pneumonia [35,36]. Once placed in the market, several other uses have been investigated: nosocomial pneumonia, diabetic foot infections, emergency therapy for MDR pathogens, nosocomial urinary tract infections, and Clostridium difficile infections [26]. A disadvantage of tigecycline is its exclusive parenteral use due to its poor bioavailability [37].

Omadacycline is one of the newest and most popular tetracyclines and the first in the aminomethylcycline subclass [3,38]. It has a broad spectrum of activity, proving in vitro effects against Gram-positive and Gram-negative bacteria, anaerobic bacteria, and atypical bacteria. In addition, the activity of this compound extends to methicillinresistant Staphylococcus aureus (MRSA); penicillin-resistant, MDR Streptococcus pneumoniae; and vancomycin-resistant enterococci [22]. Unlike tigecycline, omadacycline is available for both oral and parenteral administration. Both forms were approved in 2018 by the 
FDA for the treatment of complicated intra-abdominal and complicated skin and soft tissue infections and community-acquired pneumonia. Currently, omadacycline is in phase II of clinical trials to treat urinary tract infections, such as acute pyelonephritis and cystitis [38]. The pharmaceutical product Nuzyra was approved in the United States of America (USA) [39].<smiles>CN(C)c1cc(NC(=O)CNC(C)(C)C)c(O)c2c1CC1CC3C(N(C)C)C(O)=C(C(N)=O)C(=O)C3(O)C(O)=C1C2=O</smiles>

Tigecycline<smiles>CN(C)C1C(O)=C(C(N)=O)C(=O)C2(O)C(O)=C3C(=O)c4c(O)c(NC(=O)CN5CCCC5)cc(F)c4CC3CC12</smiles>

Eravacycline<smiles>CN(C)c1cc(CNCC(C)(C)C)c(O)c2c1CC1CC3C(N(C)C)C(O)=C(C(N)=O)C(=O)C3(O)C(O)=C1C2=O</smiles>

Omadacycline<smiles>CON(C)Cc1ccc(O)c2c1CC1CC3C(N(C)C)C(O)=C(C(N)=O)C(=O)C3(O)C(O)=C1C2=O</smiles>

Sarecycline

Figure 3. The chemical structure of the representatives of the third-generation tetracyclines.

Eravacycline is a synthetic fluorocycline, obtained by total synthesis, that contains a basic chemical structure of the tetracyclines class [40,41]. In addition, particular modifications on the $\mathrm{D}$ ring of the naphtacen nucleus were introduced. Those chemical optimisations give it a remarkable activity against Gram-positive and Gram-negative bacteria that developed specific resistance mechanisms to the tetracycline antibiotic class to treat complicated intra-abdominal infections in adults. It is available for parenteral administration in many countries in Europe, as well as in the USA [41].

Sarecycline is an analogue of tetracycline specifically designed for the treatment of acne [42]. It is available as an oral formulation to treat inflammatory lesions of moderate to severe non-nodular acne vulgaris. The main advantage of this new tetracycline is a higher selective activity against Cutinebacterium acnes comparative to older tetracyclines (doxycycline and minocycline) used in acne therapy. Due to this selectivity, the probability of developing antibiotic resistance is lower than minocycline and doxycycline [43]. Sarecycline was developed by Paratek Pharmaceuticals and Allergan but acquired by Almirall S.A by purchasing the dermatological portfolio [44]. The FDA approved sarecycline in 2018 under the trade name Seysara [45,46].

\section{Research Methodology}

The relevant primary data were found on Clarivate Analytics and ScienceDirect databases using the following keywords: (i) topic: "tetracyclines", "antibacterials"; (ii) title: "tigecycline", "omadacycline", "eravacycline", "sarecycline", and other classic derivatives of the tetracycline class. In the second stage, the articles were selected if they comprised development of tetracyclines class, physicochemical properties, aspects related to structure-activity relationships, new tetracyclines design, mechanism of action, antibacterial spectrum, therapeutical value, safety profile, bacterial resistance, and new derivatives in development. The paper includes significant references, including the latest articles published in 2021.

All chemical structures were drowned with Biovia Draw 2019 (San Diego, CA, USA) [47]. 


\section{Overview of Modern Tetracyclines}

This paper's primary targeted the new tetracyclines classified as the third generation: tigecycline, omadacycline, eravacycline, and sarecycline.

\subsection{Considerations Regarding the Chemical Structure and Physicochemical Properties of the New Tetracyclines}

Recently introduced compounds in the tetracycline class contain the basic chemical structure specific to this class, four condensed rings (A, B, C, and D) into a naphtacencarboxamide system. Other common structural elements are a dimethyl-amino group at the $\mathrm{C} 4$ position, an amidic group at the $\mathrm{C} 2$ position, a keto-enol alternation system (C11, C12, and 12a positions), and asymmetric carbons at the junction of rings A-B (stereochemical configurations) (Figures 1 and 3) [21,48,49]. X-ray crystallography of tetracycline, doxycycline, and sancycline revealed that the $\mathrm{C} 2$ amide group is oriented to form an intramolecular hydrogen bond with oxygen atom from C3 position [50]. The above elements are considered the minimum pharmacophore (6-deoxy-dimethyltetracycline) required for antimicrobial activity and a start point for inserting other substituents [21,48,49].

Depending on the radicals grafted on the tetracyclic system, these new molecules introduced on the market after 2000 present different physicochemical and pharmacological characteristics and changes in the antimicrobial spectrum [13,21,38,41,44]. The optimisation of the basic structure consisted of C7 and C9 substitutions. Position C7 is subject to substitution with electron acceptor or donor groups [40]. Thus, tigecycline and omadacycline have a dimethyl-amino group in this position. Eravacycline has a fluorine atom at the C7 position, being an electron-withdrawing substituent [40,51]. In the same place, sarecycline has a more voluminous radical, methoxy-methyl-amino-methyl [42]. The radicals in the $\mathrm{C} 9$ position are distinct for each of the new representatives. Tigecycline and eravacycline are synthetic analogues that contain a glycyl-amide substituent [40,52].

Tigecycline was synthesised by adding a tert-butyl-glycyl-amide substituent, while in eravacycline this group was replaced with a pyrrolidinyl-acetamide group [32,40]. However, tigecycline is an analogue of minocycline formed by adding the tert-butyl-glycylamide substituent at the C9 position (Figure 4). It is the first glycylcycline tetracycline discovered [29,31]. Currently, tigecycline is manufactured as a lyophilised powder form because it undergoes a degradation process. Tigecycline is commercialised under the trade name Tygacil (pharmaceutical form for intravenous infusion). The recommended doses regimen is $100 \mathrm{mg}$ initial dose, followed by $50 \mathrm{mg}$ every $12 \mathrm{~h}$ [31].<smiles>CN(C)C1=C(O)C(C(N)=O)=C([O-])[C@@]2(O)C(O)=C3C(=O)c4c(O)c(NC(=O)CNC(C)(C)C)cc(N(C)C)c4C[C@H]3C[C@@H]12</smiles>

Figure 4. The chemical structures of the tigecycline and conventional numbering.

Omadacycline (sin. amadacycline) is the first aminomethylcycline of this new subclass, for which the glycyl-amide group was changed to an alkyl-amino-methyl group [38,53,54]. The optimisation at the C9 atom was based on a methyl(2,2-dimethylpropylamino) fragment that replaces the glycylamide group present in the case of its homologues (tigecycline and eravacycline) (Figure 5) [52]. Omadacycline is formulated as tosylate salt for intravenous or oral administration under the trade name Nuzyra [38]. 
<smiles>CN(C)c1cc(CNCC(C)(C)C)c(O)c2c1C[C@H]1C[C@H]3C(N(C)C)C(O)=C(C(N)=O)C(=O)[C@@]3(O)C(O)=C1C2=O</smiles>

Figure 5. The chemical structures of the omadacycline and conventional numbering.

The primary structure of tetracyclines is maintained in the chemical structure of eravacycline, which is an analogue of tigecycline, with two changes on the $\mathrm{D}$ ring: the addition of a fluorine atom in the $\mathrm{C} 7$ position and the substitution of the tert-butyl-aminoacetamide group in the C9 position with a pyrrolidin-acetamido group (Figure 6) [41]. Pharmaceutical formulation under the trade name Xerava contains eravacycline, powder for concentrate for solution for infusion (50 $\mathrm{mg}$ and $100 \mathrm{mg}$ ) for intravenous use [55].<smiles>CN(C)C1C(O)=C(C(N)=O)C(=O)[C@]2(O)C(O)=C3C(=O)c4c(O)c(NC(=O)CN5CCCC5)cc(F)c4C[C@H]3C[C@H]12</smiles>

Figure 6. The chemical structures of the eravacycline and conventional numbering.

Sarecycline has no substitute in the C9 position [56]. Sarecycline is chemically distinguishable from other tetracycline-class antibiotics by the 7 [[methoxy(methyl)amino]methyl] group attached at the $\mathrm{C} 7$ position of the ring $\mathrm{D}$. This stable modification represents the longest and the largest C7 moiety among all of the tetracyclines (Figure 7). Sarecycline inhibits bacterial ribosomes through interactions with the mRNA as a consequence of C7 optimisation. This new tetracycline blocks accommodation into the A site of the first aminoacyl transfer RNA and appears to be a more potent initiation inhibitor comparative to previous analogues [57]. Sarecycline is manufactured as hydrochloride salt [42]. Pharmaceutical formula Seysara tablets for oral use contains sarecycline $(60 \mathrm{mg}, 100 \mathrm{mg}$, $150 \mathrm{mg}$ ) [46].<smiles>CON(C)Cc1ccc(O)c2c1C[C@H]1C[C@H]3[C@H](N(C)C)C(O)=C(C(N)=O)C(=O)[C@@]3(O)C(O)=C1C(=O)C2=O</smiles>

Figure 7. The chemical structures of the sarecycline and conventional numbering.

Essential physicochemical properties of the third generation tetracyclines are shown in Table S4 (Supplementary Materials).

Tetracyclines are optically active substances. The X-ray diffraction analysis (XRD) established the stereochemistry of the basic structure of these compounds. Depending on 
substitution, several chiral atoms are C4, C4a, C5, C5a, C6, and C12a (Figure 8a). Some derivatives, such as oxytetracycline and doxycycline, have six chiral carbon atoms, due to the $\mathrm{C} 5 \alpha$-hydroxyl substituent. Moreover, a conjugated system is known in the naphtacene nucleus (C10 to $\mathrm{C} 12 ; \mathrm{C} 1$ to $\mathrm{C} 3)$ [58].

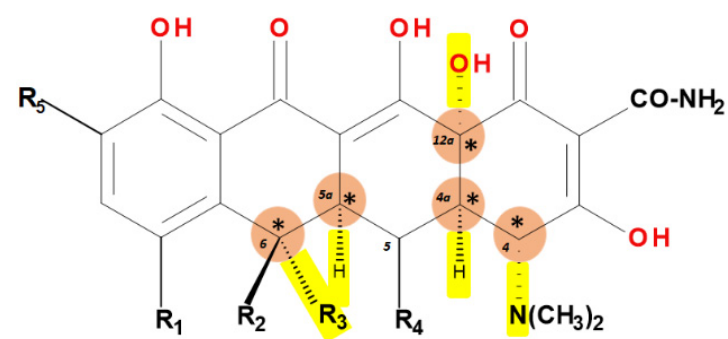

(a)

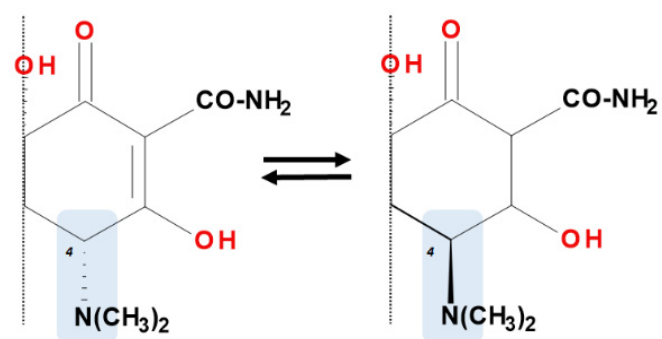

(b)

Figure 8. The chiral atoms on the chemical structure of tetracyclines and conventional numbering (a); epimerisation of tetracyclines $(\mathbf{b}) ;{ }^{*}$ - chiral centers.

In acidic conditions, tetracyclines epimerase reversibly at the $C 4$ position (Figure $8 b$ ). The resulted isomers are known as "epitetracyclines", founded in equal amounts after establishing the equilibrium. The formation of 4-epitetracyclines is notable because they are less active than non-epimerised isomers [58,59].

Tetracyclines are amphoteric compounds due to the characteristic structural elements (hydroxyls and dimethylamino substituents and the conjugated keto-enolic system). In reaction with an acid or a base, tetracyclines form salts. In pharmaceutical formulations, tetracyclines are most commonly used in the form of hydrochloric salts (e.g., eravacycline, sarecycline). Depending on the solvent, the tetracyclines' structure changes from an ionised to a non-ionised state (protonation-deprotonation equilibria). At the neutral $\mathrm{pH}$, tetracyclines mainly adopt the zwitterion form. It is known that acid salts of tetracyclines exhibit a minimum of three acidity constants in aqueous solutions $[14,50,59,60]$.

The main protonation sites of tetracyclines are the tricarbonyl system (C1-C2-C3), phenolic diketone-system (C10-C11-C12), and dimethylamino group (C4) (Figure 9) [58,61-63]. Depending on the substituents on the basic chemical structure, the protonation state of the compound also changes [64]. Tetracyclines are multiprotic compounds. Put simply, tetracyclines can be considered to behave similar to triprotic acids [63]. Other authors have suggested that tetracyclines have four ionisation equilibria and four correspondent $\mathrm{pKa}$ values (at $\mathrm{pH}$ values of 3.2, 7.6, 9.6, and 12) and five protonation states [63].

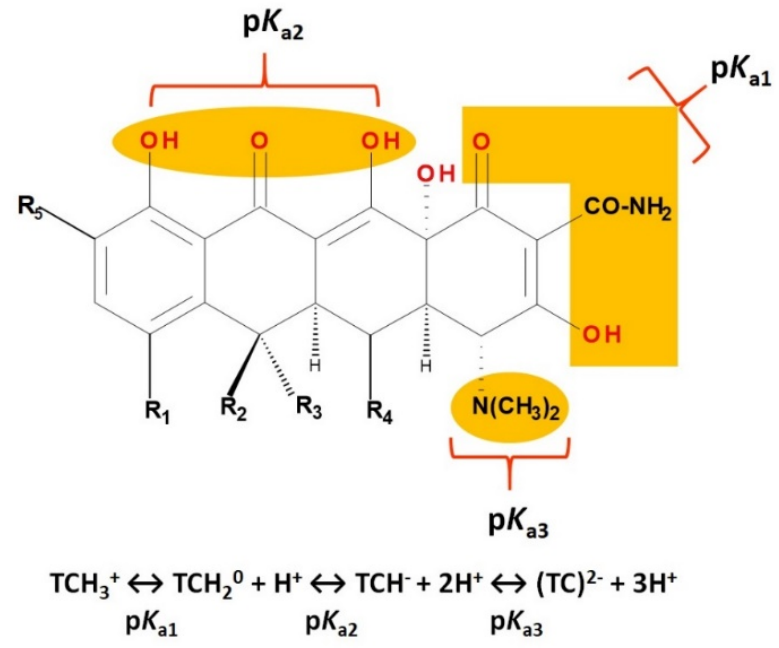

Figure 9. The tetracycline (TC) structural sites and the correspondent acidic dissociation constants [61-65]. 
Thus, tigecycline poses five main ionisation groups, specifically, five values of $\mathrm{p} K_{\mathrm{a}}$ (at $\mathrm{pH}$ values of 2.8, 4.4, 7.4, 8.9, and 9.5), an important role having the substitutes from $\mathrm{C} 7$ and C9 [65]. Using MarvinSketck (ChemAxon, Budapest, Hungary) for sarecycline, researchers found 17 possible microspecies depending on the $\mathrm{pH}$ value. Table 2 comprises the predicted microspecies and the highest value of ionisation (\%) at a specific $\mathrm{pH}$; additionally, the degree of ionisation at the physiologic $\mathrm{pH}(7.4)$ was highlighted. The highest ionisation percentages of the microspecies were identified as follows: no. 3 at $\mathrm{pH} 0-1(98.15 \%)$, no. 6 at $\mathrm{pH} 4(98.66 \%)$, no. 14 at $\mathrm{pH} 11(96.30 \%)$, no. 17 at $\mathrm{pH} 14(95.55 \%)$, and no. 7 at $\mathrm{pH} 8.6$ $(49.38 \%)$. At the physiologic $\mathrm{pH}(7.4)$, no. 2 was $21.59 \%$, the highest ionisation percentage.

Table 2. Sarecycline microspecies and the degree of ionisation as a function of $\mathrm{pH}$ (calculated) [66].

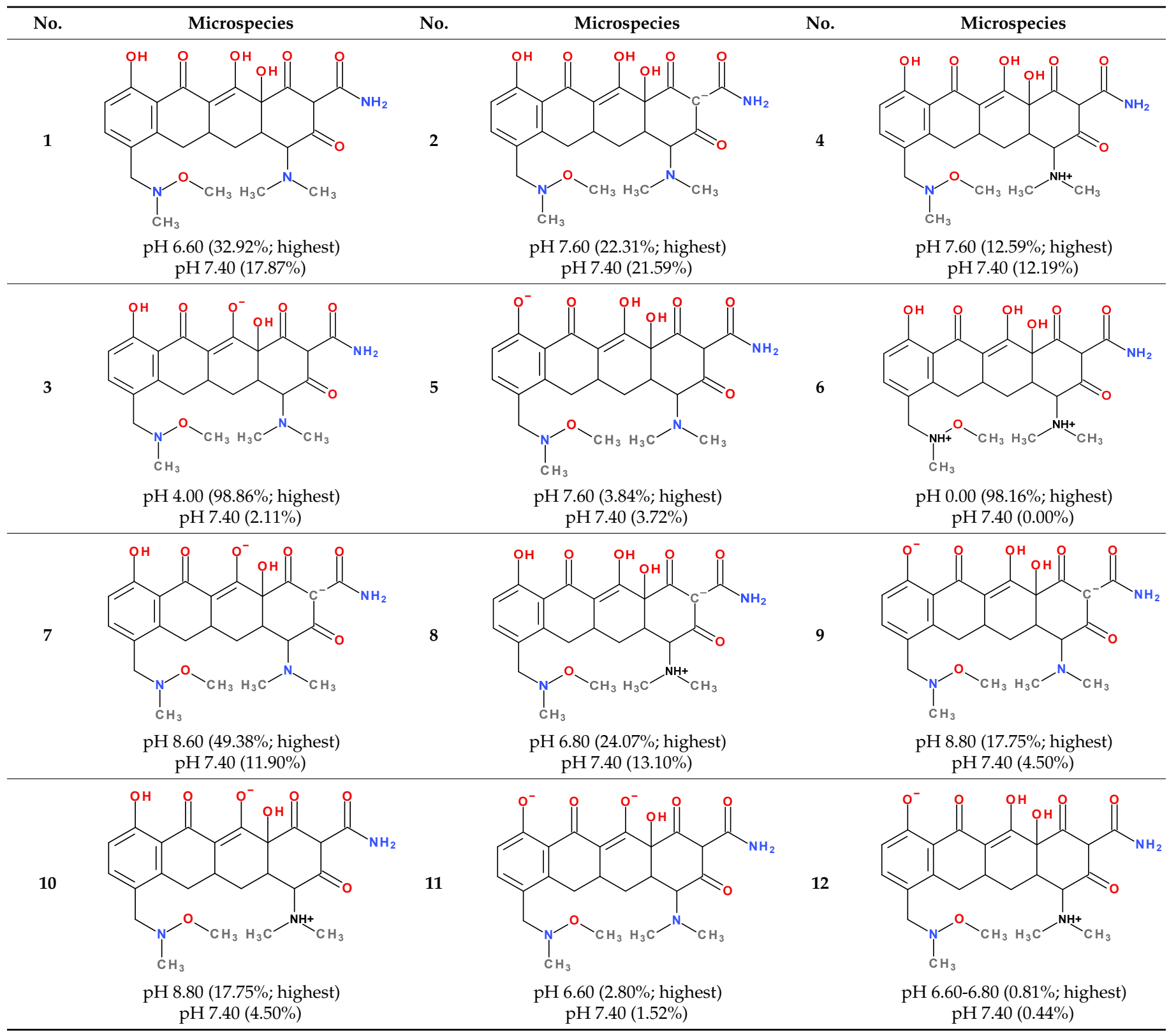


Table 2. Cont.

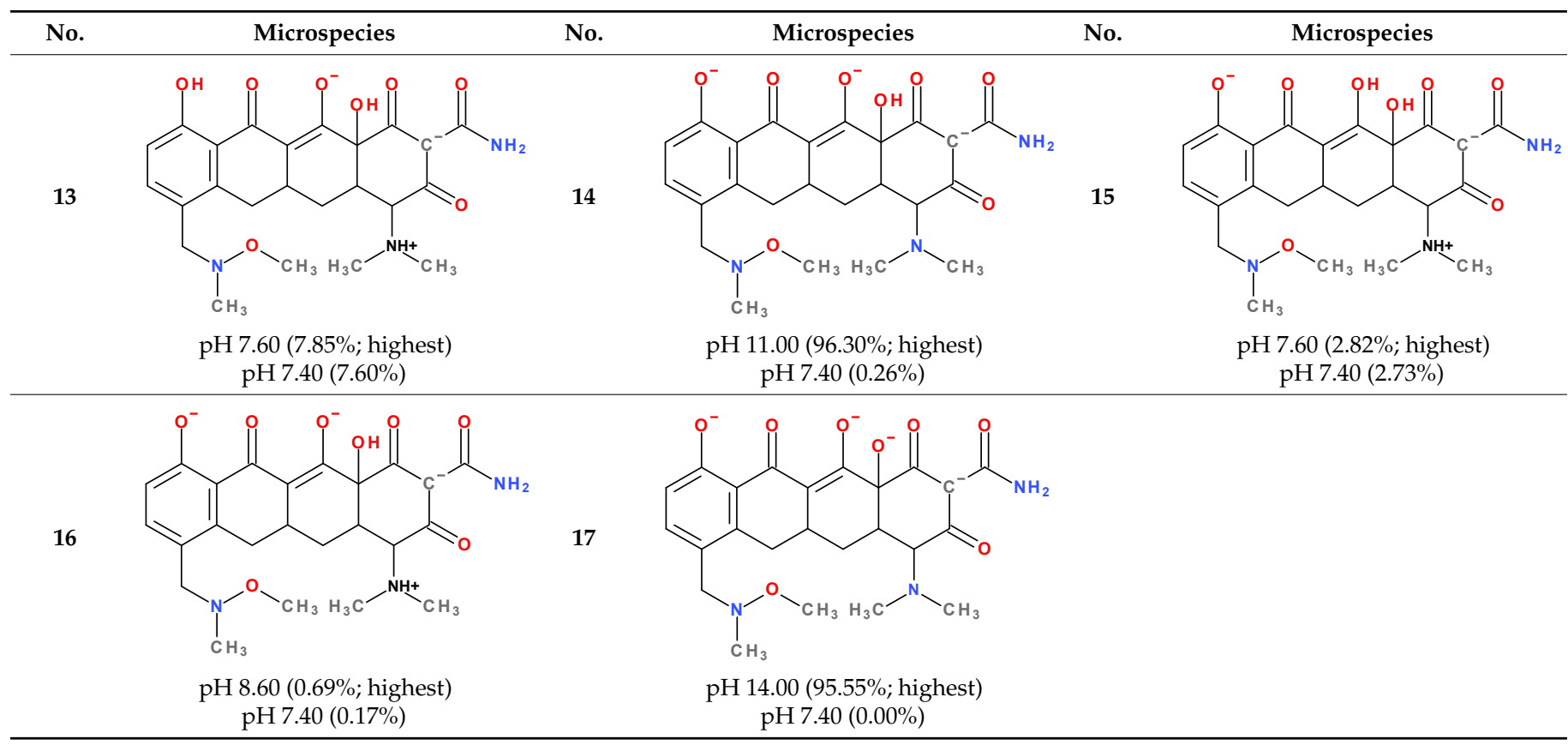

Protonation equilibria and formed microspecies play an essential role in the bioavailability of tetracyclines [63]. The protonated state of tetracyclines is also essential in the analysis. For example, in electrospray mass spectrometry, both protonated molecules of tigecycline ( $\mathrm{MH}+$ and $\mathrm{MH}_{2}{ }^{2+}$ ) are predominantly formed [67].

Electron-rich functional groups depending on $\mathrm{pH}$ can be protonated or deprotonated. Consequently, the tetracyclines have excellent chelating properties with several bivalent or trivalent metal cations [60]. Thus, tetracyclines form stable complexes with metal ions due to the characteristic substituents (Table S3-Supplementary Materials) [60].

First-generation tetracyclines form insoluble complexes with metal ions $\left(\mathrm{Ca}^{2+}, \mathrm{Mg}^{2+}\right.$, $\mathrm{Fe}^{3+}$, and $\mathrm{Al}^{3+}$ ) and consequently present reduced absorption [49]. Doxycycline and minocycline (second generation) are known for their excellent ability to chelate $\mathrm{Fe}^{3+}$. Both doxycycline and minocycline absorption are impaired by ferrous sulphate; bismuth; and other antacids containing aluminium, calcium, and magnesium salts, such as coadministration of pharmaceuticals with $\mathrm{Fe}^{3+}$ and antacids (rich in $\mathrm{Ca}^{2+}, \mathrm{Mg}^{2+}$ ) $[49,68]$.

Minocycline (second generation) and tigecycline (third generation) are more chelated by $\mathrm{Ca}^{2+}$ than tetracycline due to the $\mathrm{C} 7$ dimethylamino group. This moiety increased the electron density at the $\mathrm{Ca}^{2+}$ coordination site for the two studied tetracyclines. In addition, it was observed that tigecycline formed a different higher-order complex comparative to minocycline through the $\mathrm{C} 9 \mathrm{~N}$-t-butylglycylamido substituent in $\mathrm{Ca}^{2+}$ coordination [65]. Complexes with magnesium ions inhibit bacterial growth by impairing protein synthesis; these tetracycline complexes with magnesium act by binding to the $30 \mathrm{~S}$ ribosomal subunits [69]. In plasma, tetracyclines are mainly chelated with $\mathrm{Ca}^{2+}$ and $\mathrm{Mg}^{2+}$ ions. A known mechanism of bacterial resistance to tetracyclines involves metal complexation. A possible strategy to combat bacterial resistance is to use in therapy the metal complexes of tetracycline (e.g., $\mathrm{Pt}^{2+}$ or $\mathrm{Pd}^{2+}$ complexes) $[69,70]$.

\subsection{Structure-Activity Relationships}

As a result of studies of the relationship between chemical structure and biological activity, several aspects related to the class of tetracyclines are already known $[3,13,48,49,71]$. Next, the structural elements with an impact on the biological properties of the new tetracyclines are targeted. 
Tigecycline was discovered as a result of chemical structure-activity studies [72]. Due to structural modifications made to C9 position (Figure 10), tigecycline has an affinity for the ribosomal target five times higher than tetracycline or minocycline. Therefore, this change is responsible for broadening the antibacterial spectrum and combating ribosomal protection, one of the two mechanisms of bacterial resistance specific to tetracycline $[29,73,74]$. Moreover, this radical is a bulky steric hindrance that prevents the expulsion of the substance out of the bacterial cell by effluent tet proteins, thus reducing the susceptibility of developing antibiotic resistance $[28,75]$.

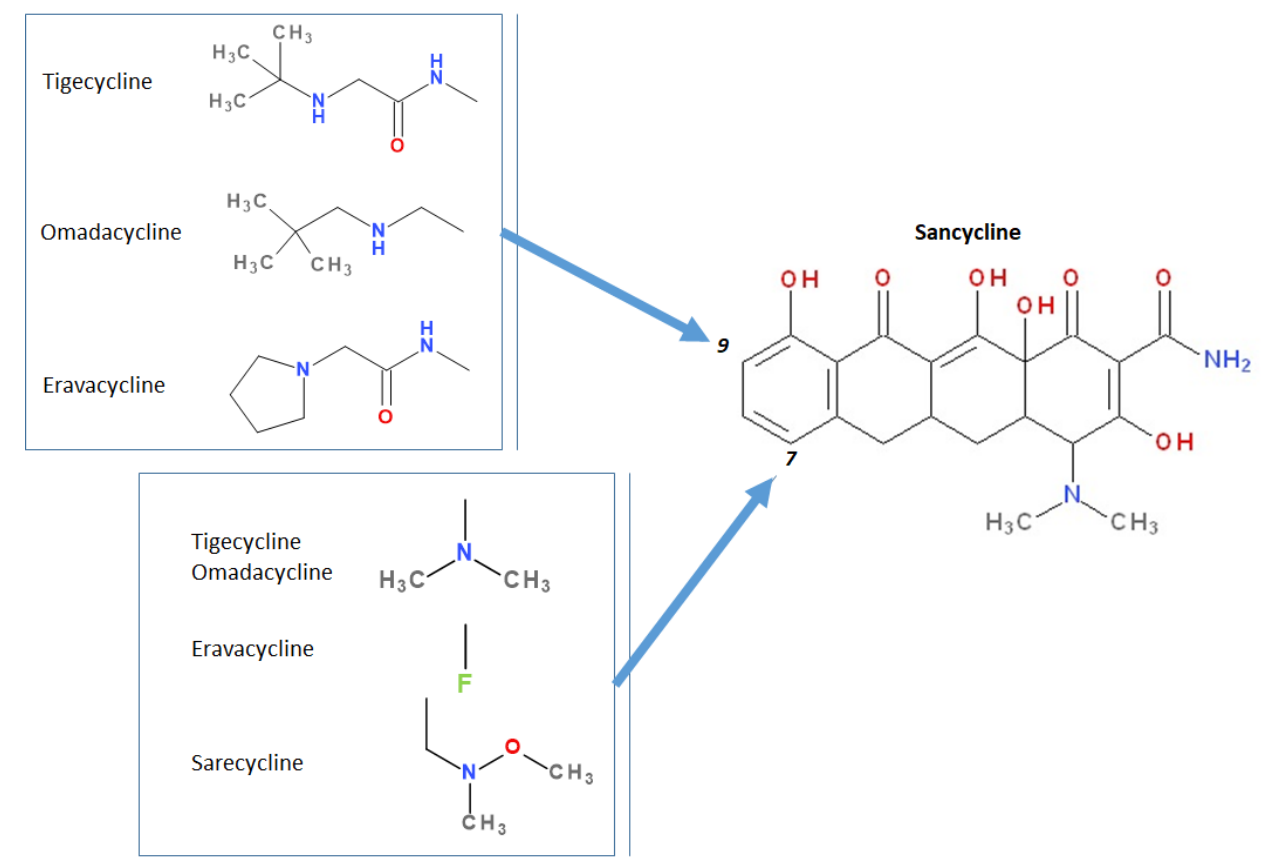

Figure 10. Optimisation of $\mathrm{C} 7$ and $\mathrm{C} 9$ positions in the development of new tetracyclines.

Researchers observed some structural features of glycylcyclines that are essential in maintaining biological activity [13]. A critical element is the basic nitrogen atom from the glycyl unit; derivatives containing low volume alkyl-amino or cyclic amine groups have shown optimal results. Attempts to replace the radical from the C9 position with other amino acids such as alanine, phenylalanine, and leucine failed because the resulting compounds were much less effective [72]. Similarly, substitutions with smaller groups than the tert-butyl-amino group led to compounds with low potency, while the attempt to substitute the amine with n-propyl, n-butyl, and n-hexyl has not brought improvements [76]. The antimicrobial activity and the pharmacokinetics of tigecycline are considerably influenced by the ability to form complexes with metal ions (calcium, magnesium, and iron). The target of the cations is the keto-enol system (C11 and C12 positions), the enol in position $\mathrm{C} 1$, and the carboxamide in position $\mathrm{C} 2$. Therefore, water-insoluble chelates are formed with a low absorption [13].

Chemical modulations performed to obtain omadacycline on C9 led to an increase in antimicrobial potency by overcoming the resistance to the efflux mechanisms and overcoming ribosomal protection [22,77]. Furthermore, the aminomethyl moiety from C9 position provides improved pharmacokinetic parameters, such as dose reduction (high doses cause side effects such as nausea and vomiting, often encountered in C9 glycylcyclines), and, in particular, oral bioavailability [78]. Due to these changes, omadacycline has a pharmacokinetic profile (absorption, distribution, metabolism, and excretion, ADME) that distinguishes it from the glycylcycline subgroup [77].

A study was conducted on aminomethycyclines with in vitro potency (with a minimum inhibitory concentration (MIC) $\leq 0.06-2.0 \mu \mathrm{g} / \mathrm{mL}$ ) against Gram-negative bacteria 
with different mechanisms of resistance by ribosomal protection (Tet(M)): Staphylococcus aureus, Enterococcus faecalis, and Streptococcus pneumoniae, and on the efflux mechanisms Tet(K) in Staphylococcus aureus, Tet(L) in Enterococcus faecalis) [51]. Compounds with lipophiliaenhancing or benzyl substitutions in the aminomethyl side group showed the highest potency against ribosomal alteration and efflux of resistant strains. However, high-polarity analogues or electrically charged groups, as well as acyl derivatives, showed a significant decrease in antibacterial activity. Although alkyl substituents (e.g., tert-butyl group) showed moderate potency, they were chosen for further optimisation and screening. It was found that analogues with the alkyl group, which extend with at least three carbon atoms to the aminomethyl group; those with branched alkyl chains; and piperidine analogues have superior activity. The ramification in the alkyl chain from position 1 has a detrimental impact due to steric hindrance. The introduction of two methyl groups in position 2 showed a significant improvement in antibacterial activity. Finally, residues containing more than five carbon atoms had reduced activity in the presence of plasma, indicating a high percentage binding to plasma proteins [38,51].

Therefore, following classical studies on the chemical structure-biological activity relationships, omadacycline, a compound containing a neopentyl moiety in the aminomethyl group, has been identified as the most valuable aminomethylcycline in this series, becoming a new subclass of tetracyclines [77].

It has been observed on fluorocyclines that as the substituents attached to the carbon atom at the $\mathrm{C} 9$ positions are more polar or more basic, the microbiological activity of the compound will increase, especially on Gram-negative bacteria. A study conducted in 2012 examined the behaviour of analogues of 7-fluoro-9-amino-acetamido-6-demethyl6-deoxytetracyclines on various Gram-negative and Gram-positive bacteria, but also on gene isolates resistant to tetracycline class [79]. In general, less voluminous secondary or tertiary amine analogues from C9 position were found to have a lower MIC compared to analogues with substituents such as aromatic amines or alkylamines with lower basicity. Compared to tertiary alkylamine, dimethyl, azetidine, and piperidine analogues, eravacycline, a compound bearing a pyrrolidine nucleus, showed a 8 to 16 times higher potency against $K$. pneumoniae (tet(A)) and 4 to 8 times higher potency against $E$. coli (tet(A)). In addition, eravacycline is 4 to 64 times more potent than piperidine and azetidine omologues against bacterial isolates that have been tested (except for S. pneumoniae expressing or not expressing tet( $\mathrm{M})$ protein, were it showing an equivalent response). The addition of polar substituents, fluorine atoms, or pyrrolidine bicycles produced no improvements, but neither did negative influence on the activity against pneumococcal bacteria when compared to unsubstitued pyrrolidine analogues $[40,80]$. The pyrrolidine substituent at the $\mathrm{C} 9$ the fluoro substituent at $\mathrm{C} 7$, the main optimisations in eravacycline, positively influenced the potency and the antibacterial spectrum [19].

Unlike other tetracyclines, the chemical structure of sarecycline includes a unique modification at the $\mathrm{C} 7$ position (the longest and most voluminous of the whole class), a 7-[(methoxy-(methyl)-amino)-methyl]methyl group (Figure 10). As a result of this chemical optimisation, the activity of this compound is enhanced, binding to the codon of the A site, interfering with the movement of messenger RNA (mRNA) along the channel, or disrupting the codon A-anticodon interaction [42].

The substituted tetracycline system at positions $\mathrm{C} 7$ and $\mathrm{C} 9$ is the basis of compounds with increased antibacterial activity, while any modification made at the C1-C4, C10-C12, C-11a, and C-12a will have a negative consequence on their action. Other important aspects regarding the relationship between chemical structure and biological activity are presented in Figure $11[3,38,40,51]$.

In addition, tetracyclines contain a $4 \mathrm{~S}(\alpha)$-dimethyl-amino group in the $\mathrm{C} 4$ position, an absolute necessity for optimal antibacterial activity. On the other hand, the epimerisation of the $4 \mathrm{R}(\beta)$ isomer will lead to a decrease in antibacterial activity, especially against Gramnegative bacteria. The epimerisation process from position $\mathrm{C} 4$ takes place during harsh 
chemical reactions, in vivo metabolism phenomenon, but also under changes in the $\mathrm{pH}$ values [25].

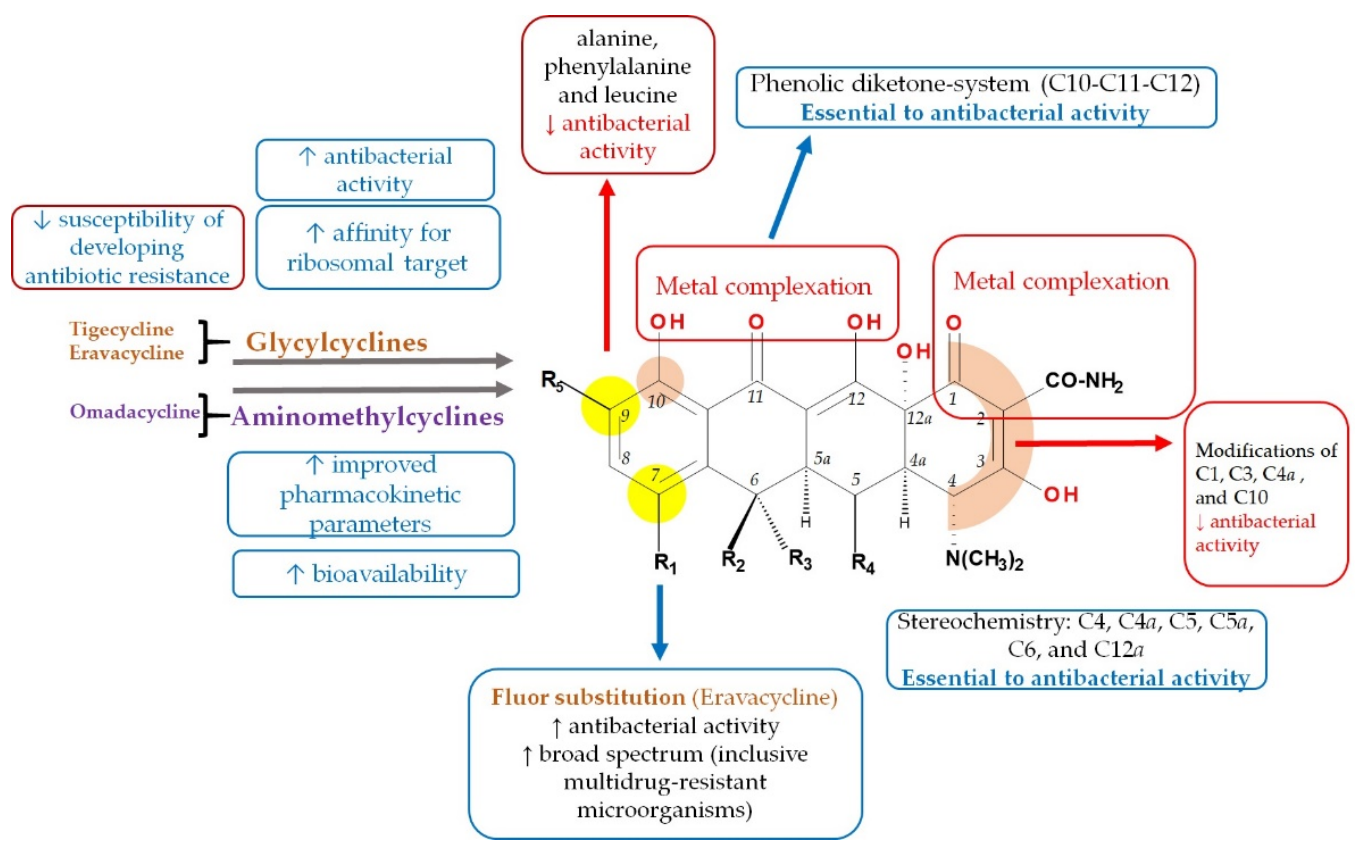

Figure 11. The essential relationship between chemical structure and biological activity of modern tetracyclines.

The C4 $\beta$-epimers have noticeably different properties from those of compounds with a normal configuration. The most significant difference is observed in antibacterial activity manifested in vitro. $\beta$-Epimers have been found to be responsible for approximately $5 \%$ of normal tetracycline activity. It has been observed that the epimerisation phenomenon takes place in different solvent systems, at variations of $\mathrm{pH}$ between 2 and 6 [14]. Tetracyclines are prone to epimer formation, particularly under weak acidic conditions. The epimers have distinct toxicological and antibacterial properties, and therefore selective biosynthesis is a major challenge. This is due to the fact that the epimers are isobars with the parent compound, having very similar physico-chemical properties. Epimerisation can occur in vivo, even in the bladder [59].

\subsection{Mechanism of Action}

Tetracyclines inhibit protein synthesis by inhibiting the association of aminoacyl-tRNA with bacterial ribosome $[49,75]$. Tetracyclines bind with high affinity to a specific locus (16S) on the $30 \mathrm{~S}$ ribosomal unit during translation. In this way, the penetration of aminoacyl transporter RNA (tRNA) into the acceptor site (A) on the bacterial ribosome is blocked, the consequence being the cessation in the incorporation of amino acids residues in the process of elongation of the polypeptide chain. Thus, the protein synthesis is stopped (Figure 12) $[18,81,82]$. Commonly, at therapeutic concentrations, tetracyclines are consider bacteriostatic antibiotics [18], but late studies have described their bactericidal effects in vitro, especially in the case of tigecycline (studies on mice) [83]. 


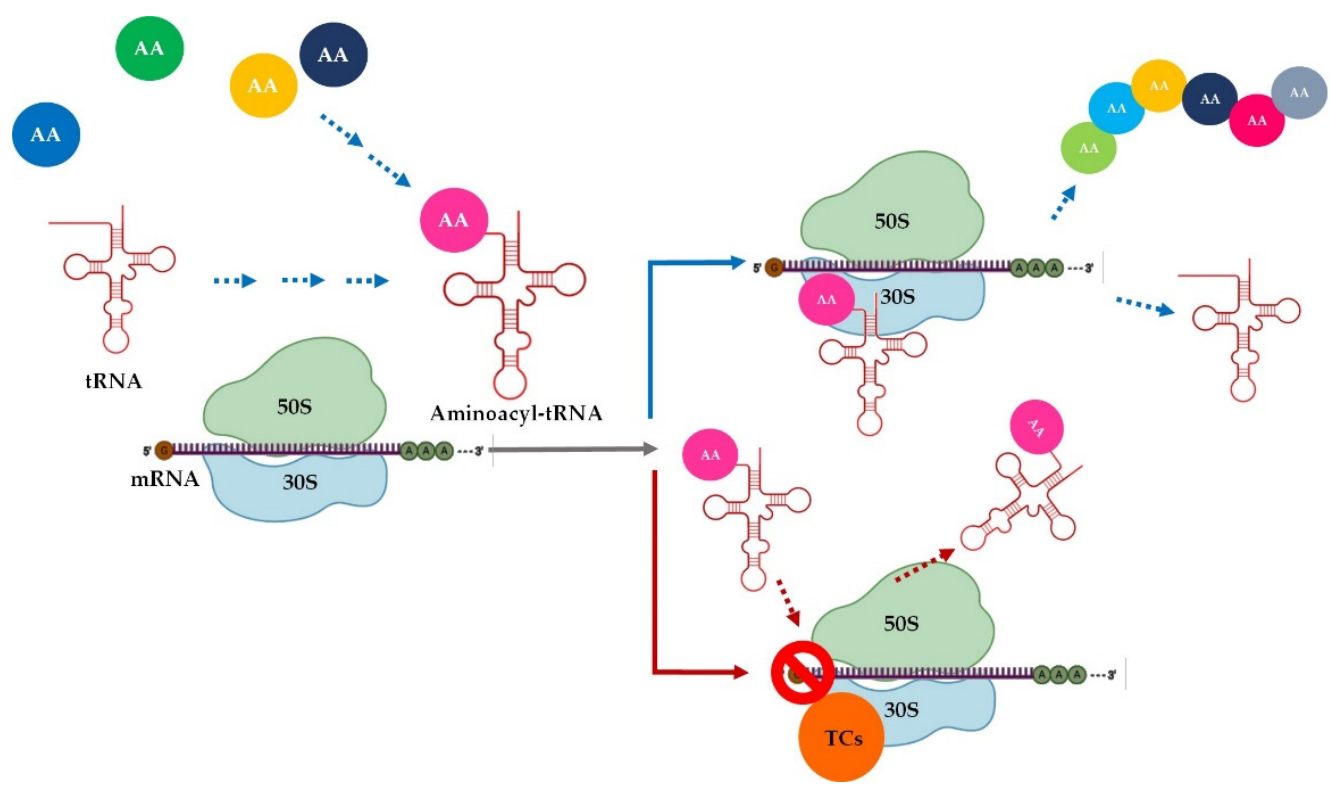

Figure 12. Scheme of the tetracyclines' mechanism of action, where AA—aminoacids, TCs—tetracyclines, tRNA—transfer ribonucleic acid, mRNA—messenger ribonucleic acid, 30S and 50S—ribosomal subunits (created with BioRender.com (accessed on 30 September 2021) [84].

It is well known that tetracyclines cross the membranes of Gram-negative bacteria through a cationic complex with $\mathrm{Mg}^{2+}$, using the OmpF and OmpC porins in the outer membrane $[38,85]$. Later on, the Donnan potential generated along the outer membrane causes the accumulation of the complex in the periplasmic space, where the dissociation from the $\mathrm{Mg}^{2+}$ ion of tetracycline takes place and there is a release of an electrically uncharged molecule that is lipophilic enough to diffuse through the inner membrane into the cytoplasm [86]. The uptake of tetracyclines in the cytoplasm is partially energydependent, involving, in addition to passive diffusion, the proton-motive force and the hydrolysis of phosphate bonds [18]. For Gram-positive bacteria, it has been reported that these agents reach the cytoplasm by passive diffusion and/or active transport. In the cytoplasm, tetracyclines chelate $\mathrm{Mg}^{2+}$ ions again and, in this form, attack the ribosomal target [75]. Hence, bivalent ions are a vital element in the transport and efficiency of these compounds [85].

Tigecycline is not affected by most common antibiotic resistance mechanisms because it binds to the $30 \mathrm{~S}$ subunit (five times stronger than tetracyclines) [28], even in the presence of ribosomal protection, being excepted from membrane efflux [87]. This is due to the voluminous substituent in the C9 position of the naphtacenic nucleus, representing a steric hindrance $[88,89]$. Tigecycline's activity was evaluated by a study on Escherichia coli derivatives containing plasmids expressing different specific efflux genes (tet $[\mathrm{B}]$, tet $[\mathrm{C}]$, and tet $[\mathrm{K}])$. An unchanged MIC value confirmed tigecycline's protection against these efflux genes [90]. Moreover, glycylcyclines also manifest resistance to less common mechanisms, such as altered target site conformation, enzymatic degradation, and mutations in DNA gyrase [87].

Similar to tigecycline, omadacycline possesses excellent activity against bacterial isolates carrying a wide variety of resistance mechanisms, including both tet $[\mathrm{K}]$ and tet $[\mathrm{O}]$ genes simultaneously $[22,91]$. Due to the reversible binding of tetracyclines to ribosomes, they act as bacteriostatic agents. Instead, in vitro omadacycline has demonstrated bactericidal activity against Haemophilus influenzae, Streptococcus penumoniae, and Moraxella catarrhalis [78]. Omadacycline has no significant effect on the synthesis of RNA, DNA, and peptidoglycan. Like tigecycline, omadacycline binds to the $30 \mathrm{~S}$ subunit of the bacterial ribosome with enhanced binding based on other molecular interactions [77]. Having a D-ring modified with a pyrrolidinacetamide side chain, eravacycline was designed 
to maintain its activity against resistant bacteria (e.g., carbapenem-resistant, MDR, and extended-spectrum cephalosporin-resistant Enterobacteriaceae and extended-spectrum, $\beta$-lactamase-producing Enterobacteriaceae) [41,92]. Eravacycline has 10 times the affinity for the ribosomal target in vitro and inhibits translation at four times lower concentrations than tetracycline [93]. A study conducted by Batool et al. in 2020 concluded that sarecycline differs slightly from other tetracycline derivatives in terms of mechanism of action, emphasising its unique role in this large family, a role that clinicians should take into account when evaluating its therapeutic potential. By analysing the crystal structure of sarecycline related to the bacterial initiation complex, it has demonstrated that in addition to binding to the same site of the small ribosomal subunit, sarecycline, due to the C7 moiety, expands and establishes uncommon interactions with mRNA. This contact leads to the stabilisation of the substance on the ribosome and an increased inhibitory effect. Thus, sarecycline overcome the mechanisms of bacterial resistance to tetracyclines [42,57].

\section{Other Biological Effects}

In addition to the approved therapeutical uses as antibiotics, tetracyclines have other biological effects, which have been investigated and exploited. These non-antibiotic properties comprise anti-inflammatory effects; anti-apoptotic activity; immunomodulatory properties; inhibitory effects on proteolysis, angiogenesis, and tumour metastasis; and a neuroprotector effect [17].

The anti-inflammatory activity of this class is mediated by a large number of mechanisms such as inhibition of neutrophil activation and migration; T lymphocyte activation and proliferation; inhibition of phospholipase, angiogenesis, nitric oxide synthesis, and granuloma formation; suppression of inflammatory cytokine release (TNF $\alpha$, IL-1 $\beta$, IL-6, IL-8); and decrease of reactive oxygen species [94,95]. However, the best-known mechanism of anti-inflammatory action is the inhibition of matrix metalloproteinases (MMPs). This mechanism occurs both directly and indirectly by inhibiting the MMPs synthesis [96]. Therefore, tetracyclines, such as doxycycline, minocycline, and sarecycline, are frequently prescribed for acne vulgaris when topical treatment is unsuccessful [94]. In a study using the carrageenan-induced rat paw oedema inflammation model, sarecycline presented an anti-inflammatory effect comparable to doxycycline and minocycline at all the tested doses [42]. Moreover, sarecycline has been proven to be a valuable alternative for treating papulopustular rosacea in terms of efficiency, safety, and tolerability [97].

The non-antibiotic properties of tetracyclines and their analogues were studied in both dermatological and non-dermatological diseases, as presented in Table 3 [98].

Table 3. Other therapeutical uses of tetracyclines related to their non-antibiotic properties.

\begin{tabular}{|c|c|c|c|}
\hline Dermatological Conditions & Reference & Non-Dermatological Conditions & Reference \\
\hline Acne & {$[99,100]$} & Rheumatoid arthritis & {$[101,102]$} \\
\hline Rosacea & {$[103,104]$} & Scleroderma & [105] \\
\hline Bullous dermatitis & [106] & Cancer & [107] \\
\hline Kaposi's sarcoma & [108] & Aortic aneurysm & [109] \\
\hline Sarcoidosis & [110] & Acute myocardial infarction & [111] \\
\hline Pyoderma gangrenosum & [112] & Periodontitis & [113] \\
\hline Hidradenitis suppurativa & [114] & & \\
\hline Sweet's syndrome & [115] & & \\
\hline Alpha-1-antitrypsin deficiency panniculitis & [116] & & \\
\hline Pityriasis lichenoides chronica (PLC) & [117] & & \\
\hline
\end{tabular}

Research has shown that minocycline has several non-antibiotic biological effects that are beneficial in experimental models of various inflammatory diseases. These include dermatitis, periodontitis, atherosclerosis, and autoimmune diseases such as rheumatoid arthritis and inflammatory bowel disease. Due to its high lipophilicity, minocycline readily penetrates the blood-brain barrier and achieves high concentrations in the brain; hence, it 
has been effective in neuroprotection. However, because of its lipophilicity, vestibular side effects such as dizziness and vertigo have been associated with minocycline therapy. This outcome has been confirmed by experimental studies of ischemia, traumatic brain injury, and neuropathic pain, as well as several neurodegenerative diseases (e.g., Parkinson's disease, Huntington's disease, Alzheimer's disease, amyotrophic lateral sclerosis, spinal cord injury, and multiple sclerosis). In addition, other pre-clinical studies have shown the ability of minocycline to inhibit malignant cell growth and activation, HIV replication, and prevent bone resorption [17].

\subsection{Spectrum of Antibacterial Activity}

Detailed antibacterial spectrum of the new generation of tetracyclines is shown in Table S5 (Supplementary Materials).

Tigecycline presents activity against MDR pathogens, such as MRSA; Staphylococcus epidermidis; vancomycin-resistant Enterococcus; Acinetobacter spp.; Stenotrophomonas maltophilia; penicillin-resistant Streptococcus pneumoniae; and Enterobacteriaceae resistant to aminoglycosides, carbapenems, fluoroquinolones, and $\beta$-lactamase producers $[118,119]$. Tigecycline is very active against Neisseria gonorhoae and Eikenella corrodens, as well as on rapidly growing species of mycobacteria (M. chelonae, M. abscessus, M. fortuitum) [120]. Although against most of tigecycline's action is bacteriostatic, there are pathogens on which it acts bactericidally, such as Legionella pneumophila and Streptococcus pneumoniae. However, tigecycline is not effective against Pseudomonas aeruginosa, Proteus mirabilis, Providencia spp., or Morganella morganii [121].

Omadacycline is very potent against atypical bacteria, as well as Gram-positive and Gram-negative aerobic pathogens [22,122,123], and further against anaerobic bacteria that cause infections from dog or cat bites (except Eikenella corrodens); however, omadacycline is not effective on the species of Proteus, Providencia, Morganella, and Pseudomonas [124]. Generally, omadacycline acts as bacteriostatic agent, but against Escherichia coli, Streptococcus pneumoniae, and Haemophilus influenzae acts bactericidal [125]. This new tetracycline is more active than tigecycline and acts similar to eravacycline against Gram-positive pathogens [40].

Eravacycline is a broad-spectrum tetracycline that has showed a great activity against aerobic and anaerobic Gram-negative and Gram-positive bacteria, except $P$. aeruginosa and Burkholderia cenocepacia. Eravacycline also shows good activity against MDR bacteria, including Enterobacteriaceae and A. baumannii, expressing extended spectrum $\beta$ lactamases, carbapenem resistance, and mechanisms conferring resistance to other antibiotic classes [18]. Eravacycline is more effective than omadacycline against Gram-negative and broad-spectrum beta-lactamase-producing bacteria. Eravacycline is two to four times more active than tigecycline on clinically relevant Gram-positive species [40].

The spectrum of sarecycline is narrow, with little activity against aerobic and anaerobic Gram-negative bacteria and microflora commonly found in the gastrointestinal tract. The activity of this compound specifically targets Cutinebacterium acnes, but also some clinically relevant Gram-positive bacteria, including MRSA [126]. It is noteworthy that the prolonged and intermittent use of broad-spectrum antibiotics such as doxycycline and minocycline in acne vulgaris has been associated with the development of antimicrobial resistance and permanent perturbation of the gut and cutaneous microbiome. Although no causal relationship has been definitively established, the use of doxycycline in patients with acne was found to be associated with a 2.25-fold greater risk of developing Crohn's disease $[127,128]$.

\subsection{Bacterial Resistance to New Tetracyclines}

The widespread use of these antibacterial agents has unavoidably led to the development of bacterial resistance through plasmid-encoded tetracycline resistance genes (tet), conjugated transposons and integrons, which allow tet genes to be transmitted from one 
species/generation to another species/generation through conjugation [13,72,129]. The four main types of tetracycline resistance are outlined in Table $4[18,27,38]$.

Table 4. Mechanisms of resistance and resistance determinants of tetracyclines.

\begin{tabular}{|c|c|c|c|c|}
\hline \multirow{2}{*}{$\begin{array}{c}\text { Resistance } \\
\text { Determinants }\end{array}$} & \multicolumn{4}{|c|}{ Resistance Mechanisms } \\
\hline & Efflux Pump & $\begin{array}{l}\text { Ribosomal } \\
\text { Protection }\end{array}$ & $\begin{array}{l}\text { Chemical } \\
\text { Inactivation }\end{array}$ & rRNA Mutations \\
\hline Gram-positive bacteria & 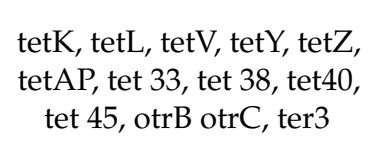 & $\begin{array}{l}\text { tetM, tet } \mathrm{O} \text {, tetP, tetQ, } \\
\text { tet } S, \operatorname{tet} \mathrm{T} \text {, tet } \mathrm{W}, \\
\text { tet } \mathrm{Z}, \operatorname{tet} \mathrm{B}(\mathrm{P}) \text {, tet32, } \\
\text { tet } 36, \text { otr } \mathrm{A}\end{array}$ & - & G1058C \\
\hline Gram negative bacteria & 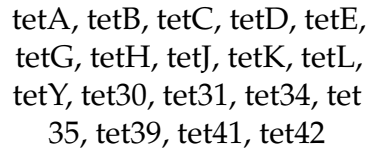 & $\begin{array}{l}\text { tetM, tetO, tetQ, tetS, } \\
\text { tetW, tet36, tet } 44\end{array}$ & tet $X$, tet34, tet37 & $\begin{array}{c}\text { A926T, A928C, } \\
\text { G927T, } \Delta \text { G942, G966U }\end{array}$ \\
\hline
\end{tabular}

The expression of these genes leads to the production of proteins that contribute to the two primary mechanisms of resistance: ribosomal protection by dissociating tetracyclines from their target (e.g., tet[M], tet[O]) and the efflux of the substance out of the cell by active transport (e.g., tet[A], tet[B]) [28,118]. The efflux pumps are located in the cytoplasmic membrane and act through the antiport of a proton in exchange with a tetracycline-magnesium monocationic complex. Thus, the intracellular concentration of tetracyclines decreases [13]. The most common pumps are part of the Major Facilitator Superfamily of carriers [75]. In contrast to efflux pumps, for which the mechanism is elucidated, the ribosomal protection mechanism is not fully known. However, studies suggest that genes involved (e.g., tet[M], tet $[\mathrm{O}]$, and tet $[\mathrm{S}]$ ) alter the conformation of ribosomes and displace the drug from the active site $[38,85,130]$. These genes are protein molecules GTPases (guanosine triphosphatases) that have structures and sequences similar to elongation factors (EF-G and EF-Tu) [131].

The other two less common mechanisms include two distinct genes that modify tetracyclines, leading to their degradation and mutations of the ribosomal $16 \mathrm{~S}$ subunit, decreasing the affinity of the compounds for the ribosomal target [27]. The first of the mechanisms, chemical inactivation, is caused by a FAD-monooxygenase encoded by the tet $[\mathrm{X}]$ and tet [37] genes. These hydroxylate the C11 position, altering its structure and coordination with the magnesium ion, and therefore the affinity for the ribosome $[38,132]$. Moreover, the hydroxylated version degrades even in the absence of enzymes [133]. Because monooxygenase uses NADPH and $\mathrm{O}_{2}$ in its activity, this resistance occurs only in aerobic organisms [27]. The second mechanism of resistance, the site-binding mutation, is found predominantly in bacteria with a small number of copies of rRNA [18]. The first case was described by Ross et al. (1998) on a bacterial strain of Propionibacterium acnes. In addition, there are innate resistance mechanisms, with some bacteria being more immune to the tetracycline class due to differences in membrane permeability. For example, Gramnegative bacteria are more resistant due to the outer wall containing lipopolysaccharide molecules [27].

Although tigecycline is not affected by the main resistance mechanisms, since its introduction in the clinic (2005), the number of pathogens that have developed resistance is continuously increasing. In Gram-negative bacteria, most cases were caused by overexpression of resistance-nodulation-cell division (RND) pumps. For example, MexXY-OprM for Pseudomonas aeruginosa strains and AdeIJK/AdeABC for Acinetobacter baumannii [134-137]. Something similar occurs for some Gram-positive bacteria by overexpressing the Multidrug and Toxic Compound Extrusion (MATE) (case of MepA pump for Staphylococcus aureus) [138]. Other mechanisms also decrease the susceptibility of tigecycline to other microorganisms: mutations in ribosomal protein genes, mutations in the $16 \mathrm{~S}$ subunit of rRNA [139], inactivation by FAD-dependent monooxygenase [140], and tet $X$ gene-carrying plasmids [141]. A recent study on Acinetobacter baumannii found a resistance plasmid 
containing the tet $(X 5)$ gene, with similarity regarding structure and function of other tet $(X)$ variants, probably using the same transfer elements for spreading [142].

The antimicrobial activity of omadacycline is not disturbed by the two significant resistance mechanisms in therapy [143]. This aspect is due to the functional groups in the C7 (dimethylamino) and C9 (aminomethyl) positions, which prevent the expulsion of the antibiotic by the efflux pumps and the ribosomal protection, respectively [22]. Omadacycline has demonstrated in vitro activity against bacterial strains containing efflux and ribosomal protection genes (Staphylococcus aureus expressing the tet $(\mathrm{K})$ and tet $(\mathrm{M})$ genes, Enterococcus faecalis expressing the tet $(\mathrm{L})$ and tet $(\mathrm{M})$ genes) [125]. However, the activity of omadacycline is decreased by mutations in the ribosomal RNA of some microorganisms. According to a study conducted by Heidrich et al. (2016), the MIC for tetracycline, tigecycline, and omadacycline on species containing mutations (G1055C, G996U) of the 16S ribosomal subunit increased four to eightfold, suggesting that they are susceptible to these changes, regardless to their affinity for the target $[27,144]$. The omadacycline's action and the action of glycylcyclines, in general, are also affected by chemical inactivation [27].

Eravacycline avoids tet(A) efflux pumps, maintains activity against staphylococcicontaining tet(K) genes, and successfully binds to bacterial ribosomes modified by tet( $(\mathrm{M})$ proteins $[98,145]$. However, eravacycline remains vulnerable to overexpression of MDR efflux pumps belonging to Gram-negative bacteria, change in ribosomal target (16S or 10S), and enzymatic degradation sometimes encountered in Bacterioides spp. The resistance to eravacycline has also been observed in mutant species of Enterococcus, mutations encoded by the rpsJ gene $[41,146,147]$.

In the case of sarecycline, the probability of inducing bacterial resistance is low due to the narrow spectrum of activity and the unique structural modifications at the $\mathrm{C} 7$ position. The rate of spontaneous mutations varies from $10^{-9}$ to $10^{-11}$ in Cutinebacterium acnes, and $10^{-9}$ and $10^{-8}$ in Staphylococcus aureus and Staphylococcus epidermidis, respectively (at increases in MIC values between four and eight times) [126,148].

\section{Therapeutic Use of the New Tetracyclines}

In the past, tetracyclines have been widely used for various genitourinary, gastrointestinal, respiratory tract, and dermatological diseases. However, the tremendous onset of bacterial resistance, as well as the emergence of new antibacterial agents, has diminished the area of infections for which tetracyclines are considered the first therapeutic option $[1,18,27]$.

The activity of tigecycline has been evaluated in several in vivo clinical trials in human subjects, following which the three FDA-approved indications were formulated. In the treatment of hospitalised patients with complicated skin and soft tissue infections, tigecycline has not only been shown to be effective but has also shown a favourable pharmacokinetic profile [149]. In another phase 2 open-label clinical trial, which included patients with complicated intra-abdominal infections (gangrenous perforated appendicitis, cholecystitis, diverticulitis, peritonitis), tigecycline was a safe and effective treatment [120]. Last but not least, tigecycline is indicated and approved in the treatment of communityacquired pneumonia. For all research, tigecycline met all non-inferiority criteria [31,150].

Omadacycline, unlike tigecycline or eravacycline, brings an advantage through oral formulation, facilitating patient compliance and hospitalisation costs [38]. Omadacycline is recommended in treating complicated skin and soft tissue infections and communityacquired pneumonia, but there are ongoing studies for its use in urinary tract infections [39,151-153].

Eravacycline, due to its broad antibacterial spectrum, in vitro activity, and superior tolerability in comparison with tigecycline, is an appropriate solution for treating complicated intra-abdominal infections in adults, especially when the pathogen possesses resistance mechanisms to other tetracyclines or classes of antibiotics [41]. Infection, for which the efficacy of eravacycline has been studied by comparison with the beta-lactam antibiotics 
meropenem or ertapenem, include: appendicitis, cholecystitis, diverticulitis, gastric or duodenal perforation, intra-abdominal abscess, intestinal perforation, and peritonitis [145]

The FDA-approved sarecycline is used for treating acne vulgaris in patients aged nine years or above, demonstrating efficacy against moderate-to-severe, inflammatory, or non-inflammatory (comedones) forms. In addition, due to its targeted action on $\mathrm{Cu}$ tinebacterium acnes and low blood-brain penetration, sarecycline has a good safety profile (minimal side effects), low potential to induce bacterial resistance, and also potentially low impact on the gut microbiota when compared to the broad-spectrum doxycycline and minocycline $[154,155]$.

Pharmacokinetic properties. Tigecycline is highly bound to plasma proteins and has a large volume of distribution (above plasmatic volume), which indicates its concentration in tissues. Moreover, tigecycline is rapidly distributed in tissues; the highest concentrations were observed in the bone marrow, thyroid gland, salivary glands, spleen, and kidneys. Tigecycline metabolises independent of cytochrome P450 enzymes, but not extensively. Consequently, tigecycline does not interfere with the metabolism of other substances mediated by the six cytochrome P450 isoforms (1A2, 2C8, 2C9, 2C19, 2D6, and 3A4) [31]. The pharmacokinetics of tigecycline is linear-this may be influenced by the coadministration of P-glycoprotein inhibitors or inducers; tigecycline acts as a substrate of these [156]. Similarly, omadacycline presented a low probability of interactions through transport mechanisms [133]. The omadacycline rate of absorption decreases if a high-fat meal is consumed two hours earlier. Thus, omadacycline must be taken after a fasting period of at least $4 \mathrm{~h}$, followed by $2 \mathrm{~h}$ without ingestion of drinks and food (apart from water), as well as $4 \mathrm{~h}$ without administration of antacids, multivitamins, and dairy products [157]. The liver metabolises eravacycline, but none of the metabolites are pharmacologically active. Therefore, caution is required in CYP3A4 inducers to increase the extent of eravacycline metabolism to a clinically relevant rate [41]. Sarecycline inhibits P-glycoprotein in vitro. Consequently, decreasing dose and toxicity examination is required when it is coadministered with substrate substances [56]. Generally, the pharmacokinetics of modern tetracyclines are not remarkably influenced by age, sex, or renal function (including renal failure and haemodialysis) $[29,39,158]$. The pharmacokinetic parameters of the four modern tetracyclines are shown in Table S6 (Supplementary Materials).

\section{Side Effects of the Third-Generation Tetracyclines}

As an antibiotic class, tetracyclines are generally well tolerated. However, there is a diversity of side effects and contraindications, with these compounds affecting several systems of the human body. For example, tetracyclines often cause gastrointestinal disorders such as abdominal discomfort, nausea, vomiting, and epigastric pain. Moreover, typical side effects are photosensitivity, manifested by erythema and skin blisters, discolouration of the teeth, and inhibition of bone growth in children. Rarely, tetracyclines may cause increased intracranial pressure (pseudotumor cerebri), renal toxicity, hepatotoxicity, and Clostridium difficile infections [159].

Similar to tetracyclines in the first generations, the most common side effects of modern tetracyclines are those of the gastrointestinal tract [75,160-162]. Other side effects of the tetracycline new generation are shown in Table 5. Nausea and vomiting may occur in the first two days of treatment and are usually mild to moderate. In the case of tigecycline, these effects are correlated with the dose administered, the highest tolerated doses being $100 \mathrm{mg}$ for healthy subjects without fasting, $200 \mathrm{mg}$ postprandial [156]. Diarrhoea has been reported, and is associated, in the vast majority of cases, with Clostridium difficile superinfection, ranging from mild forms to severe or fatal colitis. Other less common side effects are constipation, anorexia, dyspepsia, dry mouth, acute pancreatitis, and pancreatic necrosis $[1,31,39,46,145]$. Regarding the pharmacotoxicology of sarecycline, due to its narrower spectrum, it does not affect the intestinal flora as much, and therefore adverse effects such as diarrhoea and fungal infections have been observed less clinically [126]. 
Table 5. Other side effects of modern tetracyclines [31,33,38,39,46,145,152,154,160,163,164].

\begin{tabular}{|c|c|c|c|}
\hline No. & Affected Level/Disorders & Side Effects & Representatives (Frequency) \\
\hline 1 & Nervous system & lethargy, dizziness, dysgeusia, tinitus, vertigo & Sarecycline $(<1 \%)$ \\
\hline \multirow{3}{*}{2} & \multirow{4}{*}{ Metabolism } & \multirow{2}{*}{ hypocalcemia } & Tigecycline $(<2 \%)$ \\
\hline & & & Eravacycline $(<1 \%)$ \\
\hline & & \multirow[t]{2}{*}{ hyponatremia, hypoglycemia } & Tigecycline $(<2 \%)$ \\
\hline & & & Eravacycline $(<1 \%)$ \\
\hline 3 & Psychiatric disorders & anxiety, insomnia, depression & $\begin{array}{l}\text { Tigecycline, omadacycline } \\
\text { (insomnia only) }\end{array}$ \\
\hline \multirow[t]{2}{*}{4} & \multirow[t]{2}{*}{ Urogenital disorders } & $\begin{array}{l}\text { vulvovaginal fungal infections, vulvovaginal } \\
\text { candidiasis } \\
\text { vaginal moniliasis, vaginitis, leukorrhea }\end{array}$ & $\begin{array}{c}\text { Sarecycline, omadacycline (no } \\
\text { data available) }\end{array}$ \\
\hline & & vaginal moniliasis, vaginitis, leukorrhea & Tigecycline $(<2 \%)$ \\
\hline \multirow{2}{*}{5} & \multirow{2}{*}{ Respiratory system } & oropharyngeal pain & Omadacycline $(<2 \%)$ \\
\hline & & pleurisy, dyspnea & Eravacycline $(<1 \%)$ \\
\hline \multirow{2}{*}{6} & \multirow{2}{*}{ Others } & vertigo & Omadacycline $(<2 \%)$ \\
\hline & & abdominal pain & $\begin{array}{l}\text { Tigecycline }(>2 \%), \\
\text { omadacycline }(<2 \%)\end{array}$ \\
\hline
\end{tabular}

Tetracyclines affect teeth and bones by forming stable complexes with calcium ions, accumulating in deposits at these levels. Thus, the teeth may acquire a yellow to brown colour, sometimes even permanent, due to the formation of chelates of tetracycline-calcium orthophosphate, which darkens after exposure to the sun [126]. This phenomenon has effects from an aesthetic point of view but can be aggravated, leading to demineralisation and hypoplasia of tooth enamel with decreased resistance to caries attack [165]. Tooth staining is more common in long-term treatment with tetracycline derivatives but has also been observed with repeated short-term administrations. Children who receive tetracyclines in the first part of life and children whose mothers have used them since the second trimester of pregnancy tend to have tetracyclines deposited at the level of baby teeth. There was also a decrease in the rate of fibula growth and ossification processes for the foetus exposed in utero due to accumulation in the tissues $[39,46,145]$.

Another subgroup of side effects is skin damage. Tetracyclines may cause allergic-type side effects with pruritus, transient rash, or itchy skin and hyperhidrosis [31,145]. These reactions are due to the increased sensitivity of the skin to light during systemic tetracycline therapy. Therefore, patients undergoing treatment should avoid excessive exposure to natural or artificial sunlight (ultraviolet radiation) [46]. Hypersensitivity reactions (StevensJohnson syndrome, anaphylaxis), sepsis, and death have been reported with low frequency when using tigecycline [166].

Hepatobiliary disorders due to tetracyclines are not very common in this class but are reflected in increased plasma concentrations of aspartate aminotransferase (AST), alanine aminotransferase (ALT), bilirubin, and hepatic transaminases (TGP, TGO). Other laboratory parameters that may change are increased amylase, lipase, gamma-glutamyltransferase, urea nitrogen (class effect), creatinine phosphokinase, alkaline phosphatase, and decreased creatinine clearance. These reactions occur relatively infrequently, with a frequency $<2 \%$ for tigecycline and omadacycline, and $<1 \%$ for eravacycline (following clinical trials) $[31,39,145]$. Cases of cholestatic jaundice and mild pancreatitis induced by tigecycline have been reported $[73,167]$. At the vascular level, forms intended for the intravenous route produce reactions at the site of administration. With the exception of sarecycline (orally administration), cases of extravasation of the infusion solution, hypoesthesia, pain, erythema, swelling, inflammation, irritation, phlebitis, and thrombophlebitis have been reported $[29,39,145,168]$. Other side effects that may occur with omadacycline are cardiovascular, with grouped clinical trials showing a frequency of over $2 \%$ of hypertension and $<2 \%$ of tachycardia and atrial fibrillation. No adverse cardiovascular reactions are known for tigecycline. A study in healthy subjects showed that this compound has no significant effect on the QT interval [169]. 
At the haematological and lymphatic levels, tigecycline and omadacycline may lead to anaemia but have opposite effects on platelets, with tigecycline decreasing their number (thrombocytopenia) [170], compared to omadacycline, which may cause thrombocytosis [157]. Other common side effects of tigecycline are prolongation of partially activated thromboplastin time (aPTT) and prothrombin time. However, an increase in the international normalised ratio (INR) is less common [31].

The primary concern with tigecycline is the increased mortality due to its use, compared with other anti-infective agents [73]. The results obtained in phases 3 and 4 of 13 clinical trials alerted the FDA, which issued a black box warning about the increased risk of mortality of patients treated with this drug [171]. Consequently, several meta-analyses of all controlled and randomised clinical trials were performed, concluding that tigecycline is not indicated in severe infections and should only be reserved for use in situations where alternative treatments are not appropriate [170,172-174]. Because these studies also found higher rates of clinical failure, superinfections, and septic shock compared to the comparator group, several hypotheses were postulated in an attempt to find a cause. These could be low efficacy, low plasma concentrations (could explain persistent bacteremia), and low alveolar concentrations (partly explains the low efficacy in patients with pneumonia associated with mechanical ventilation) $[175,176]$. In addition, on the basis of animal studies (rats), eravacycline and omadacycline have been shown to have undesirable effects on fertility, affecting sperm production, maturation, morphology, and motility $[39,145]$.

During pregnancy, tetracyclines are not recommended, due to fetotoxicity and teratogenicity (tigecycline, according to the recommendations given by the FDA is classified as risk category D). Tetracyclines are used only when the benefit to the mother outweighs the potential risk for the foetus [171]. The results of animal studies indicate that tetracyclines cross the placenta, reach therapeutic concentrations in the foetal circulation, and may have toxic effects on foetal growth (often related to delayed skeletal development) [43,177]. Cases of embryotoxicity in animal models treated at the beginning of pregnancy were also highlighted. In addition, tetracyclines are excreted in human milk. Although the rate of absorption for infants is unknown, it is recommended that they not be used in breastfeeding either to avoid the risk of tooth discolouration and damage to osteogenesis $[31,39,46,145]$.

The absorption of modern oral tetracyclines (omadacycline, sarecycline), similar to older members of this class, may be affected by the concomitant use of multivitamins; antacids (containing aluminium, calcium); or those in the composition of which magnesium, iron, and/or zinc are found. In these situations, non-absorbable chelating complexes are formed. Tetracyclines may also increase the anticoagulant effect of warfarin [13]. Several reports note decreased coagulation efficiency and bleeding in some patients after starting tetracycline therapy [38]. In a pharmacokinetic-pharmacodynamic study, tigecycline decreased the clearance of warfarin, and therefore careful monitoring of anticoagulant levels is indicated by more frequent international normalised ratio (INR) and prothrombin time (PT) $[31,52,178]$. The use of tetracyclines may decrease the effectiveness of oral contraceptives, but this interaction is quite controversial due to limited information $[38,179]$. There is no clinically significant effect of sarecycline on the efficacy of oral contraceptives containing ethinyl estradiol and norethindrone acetate [46]. Other interactions recorded in the literature are increased serum digoxin concentration, interference with penicillin activity, and a synergistic effect with oral retinoids on increased intracranial pressure $[38,46]$.

\section{New Compounds under Development}

Sriram et al. (2007) synthesised tetracycline derivatives with anti-HIV, antimycobacterial, and HIV-1 integrase inhibitory properties. This was achieved by the reaction between certain tetracyclines (minocycline, tetracycline, and oxytetracycline), formaldehyde, and the secondary amine function (piperazine) of some fluoroquinolones (norfloxacin, lomefloxacin, ciprofloxacin, gatifloxacin), with the help of microwave radiation. Compound no. 10 (a tetracycline hybrid with lomefloxacin) represented in Figure 13 demonstrated the most potent effect on HIV-1 replication. These studies show that the combination of tetra- 
cyclines with fluoroquinolones has resulted in both anti-HIV and anti-tuberculosis activity (Mycobacterium tuberculosis) and has a promising prospect in treating AIDS [180,181].
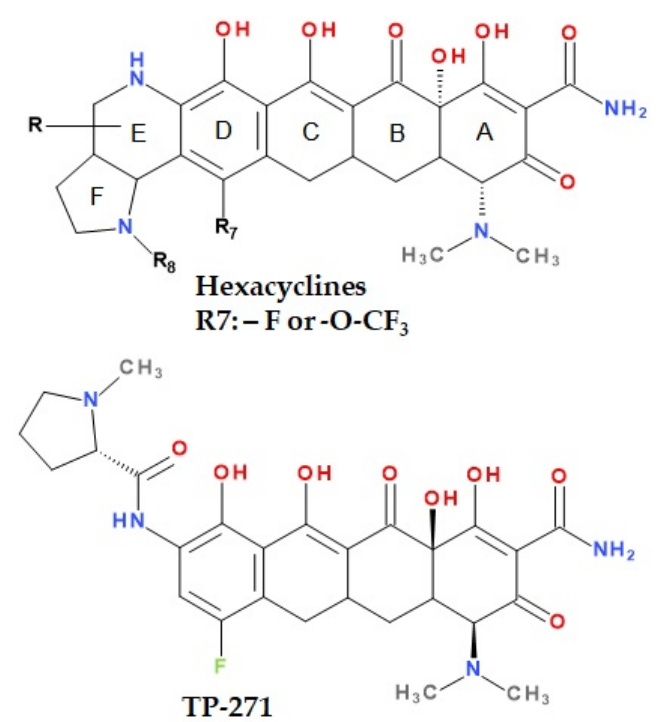

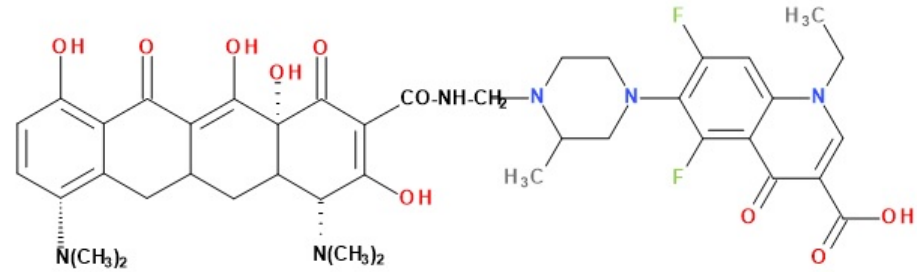

Minocycline hybrid with lomefloxacin (No. 10)

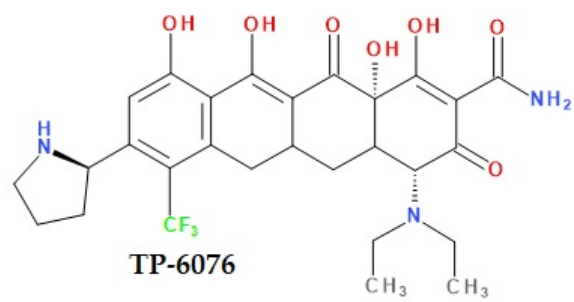

Figure 13. Promising derivatives of tetracyclines.

Using total synthesis, Sun et al. (2015) projected a series of tetracycline analogues with six fused rings called hexacyclines. Their structure consists of the classical skeleton of tetracyclines, having attached a bicyclic ring EF at the level of ring D (Figure 13) [170].

The relationships between chemical structure and antibacterial activity were tested, with substitutions in positions C7, N8, C9, and C10, evaluating the efficacy of various analogues on a wide range of Gram-positive and Gram-negative bacteria, including tetracycline-resistant or multidrug-resistant strains. Of all the compounds studied, the best results were recorded for C7-fluorohexacycline and C7-trifluoromethoxyhexacycline, with a broad antibacterial activity in vitro and good activity in vivo on Pseudomonas aeruginosa. The promising data extracted from this study support the optimisation of this type of skeleton to discover and obtain in the future some new tetracyclines that are clinically valuable [182].

Currently, Tetraphase Pharmaceuticals holds two compounds, phase I of clinical trials, TP-271 and TP-6076, whose structures are represented in Figure 13 [183-186]. Thanks to a research program opened in the mid-1990s, synthetic routes with increased scalability and efficacy of obtaining tetracycline analogues have been discovered. To date, more than 3000 analogues have been synthesised using these methods, including the two previously mentioned [187]. TP-271 is a new, clinically developing fluorocycline with promising activity against bacteria that cause respiratory infections, community-acquired pneumonia, anthrax, bubonic plague, and tularemia [187]. Following both in vivo studies and in vivo evaluations, TP-271 has shown an increased potential against susceptible and multidrug-resistant pathogens associated with moderate to severe community-acquired pneumonia. These include key bacteria in respiratory infections, Streptococcus pneumoniae $\left(\mathrm{MIC}_{90}=0.03 \mu \mathrm{g} / \mathrm{mL}\right)$, methicillin-sensitive Staphylococcus aureus $\left(\mathrm{MIC}_{90}=0.25 \mu \mathrm{g} / \mathrm{mL}\right)$, methicillin-resistant Staphylococcus aureus ( $\mathrm{MIC}_{90}=0.12 \mu \mathrm{g} / \mathrm{mL}$ ), Streptococcus pyogenes $\left(\mathrm{MIC}_{90}=0.03 \mu \mathrm{g} / \mathrm{mL}\right)$, Moraxella catarrhalis $\left(\mathrm{MIC}_{90} \leq 0.016 \mu \mathrm{g} / \mathrm{mL}\right)$, and Haemophilus influenzae $\left(\mathrm{MIC}_{90}=0.12 \mu \mathrm{g} / \mathrm{mL}\right.$ ) [185]. TP-271 has also shown strong activity against important pathogens: Yersinia pestis, Bacillus anthracis, Francisella tularensis, Burkholderia mallei, and Burkholderia pseudomallai [188]. Furthermore, TP-271 has been shown to be effective in animal studies of immunocompetent pneumonia and neutropenia with Streptococcus pneumoniae, MRSA, and Haemophilus influenzae. Regarding the mechanism of action, 
this compound binds to the $30 \mathrm{~S}$ ribosomal subunit and maintains its activity, even in the presence of the ribosomal protective protein Tet $(\mathrm{M})$. Therefore, due to the positive results obtained on animal models and the broad spectrum, TP-271 is a promising candidate for treating moderate to severe community-acquired pneumonia [185].

Tetraphase Pharmaceuticals investigated analogues of $C 4, C 7$, and $C 8$ trisubstituted tetracyclines. Thereby, some of these tetracyclines have demonstrated increased in vitro potency against clinically significant pathogens, including Acinetobacter baumannii $\left(\mathrm{MIC}_{90}=0.063 \mu \mathrm{g} / \mathrm{mL}\right)$ and carbapenem-resistant Enterobacteriaceae $\left(\mathrm{MIC}_{90}=0.5 \mu \mathrm{g} / \mathrm{mL}\right)$. The C4-positioned diethyl-amine analogue, TP-6076 (Figure 13), currently in phase I of clinical trials, showed the highest activity of all the three-substituted compounds analysed. The phase I clinical trial is focused on pharmacokinetics and safety studies to assess the bronchopulmonary disposition of intravenous TP-6076 in healthy subjects, in order to assess the potential utility in Acinetobacter baumannii pneumonia. According to Tetraphase, TP-6076 is in development for the treatment of serious and life-threatening bacterial infections. The potency of this compound on Gram-negative, multidrug-resistant bacteria is 2 to 64 times higher than that of tigecycline. TP-6076 also retains a high efficacy against isolates with intrinsic resistance mechanisms that generally affect the tetracycline class (e.g., carbapanemase-producing Enterobacteriaceae and carbapanemase-producing Acinetobacter baumannii). Antibacterial activity was not affected by the type of carbapenem resistance determinant or international clone. The increased in vitro potency also resulted in high in vivo efficiency in models of mice infected with resistant Gram-negative multi-drug isolates $[185,189,190]$.

\section{Conclusions}

The evolution of the tetracycline class is remarkable, through its development of semisynthetic analogues of the second generation, and, more recently, of the third generation. The new tetracyclines had acquired high potency and increased efficacy, even against resistant bacteria to tetracyclines. On the basis of the classical method of production, biosynthesis, and semi-synthesis, we are able to obtain the new compounds by total chemical synthesis, such as eravacycline.

The main focus in optimising the chemical structure was on modifying the C7 and C9 positions of the D ring in the simplest tetracycline with biological activity (sancycline). Thus, a new tetracycline class was discovered, based on C9-aminotetracyclines, which bear a glycyl moiety known as glycylcyclines. First in class was the tigecycline representative. Recently approved tetracyclines include beside tigecycline, omadacycline (an aminomethylcycline), eravacycline (a fluorocycline), and sarecycline (a 7-[(methoxy(methyl)-amino)-methyl]methyl] derivative).

Tigecycline has the advantage of a superior potency over Gram-positive and Gramnegative MDR bacteria; its pharmaceutical formulation is only parenteral. Omadacycline has a broad spectrum of activity, including MRSA, penicillin-resistant, MDR Streptococcus pneumoniae and vancomycin-resistant enterococci. This new tetracycline drug is more advantageous in therapy than tigecycline because it can be administered orally and parenterally. Eravacycline is a synthetic fluorocycline with a great activity against Grampositive and Gram-negative bacteria that developed specific resistance mechanisms to tetracyclines. Similar to tigecycline, eravacycline is administered exclusively parenterally. The main advantage of sarecycline is the narrow-spectrum activity and the higher selective activity against Cutinebacterium acnes. Sarecycline is available as an oral formulation to treat inflammatory lesions of moderate-to-severe non-nodular acne vulgaris.

Although tetracyclines currently act bacteriostatically, omadacycline has demonstrated bactericidal activity in vitro against some bacterial agents. It was proven that glycylcyclines manifest resistance to less common mechanisms, such as altered target site conformation, enzymatic degradation, and mutations in DNA gyrase. Therefore, eravacycline was designed to maintain its activity against resistant bacteria. Sarecycline expands and establishes uncommon interactions with mRNA. 
Currently, some studies confirm other biological effects in tetracyclines class that require in-depth future studies. Therefore, through its newly acquired members, this class of antibiotics arouses the interest of researchers in the field. Consequently, new derivatives have been already developed, and many are in development. These are studied primarily studied for the antibiotic effect and also for other biological effects.

Supplementary Materials: The following are available online at https://www.mdpi.com/article/ 10.3390/pharmaceutics13122085/s1, Table S1. The representatives of tetracyclines class from first and second generations and their approval in therapy (FDA-USA Food and Drug Administration, EMA-European Medicine Agency, MHRA-UK Medicines and Healthcare Products Regulatory Agency). Table S2. Modern tetracyclines of the third generation introduced in therapy. Table S3. Essential structural features of tetracycline antibiotics. Table S4. Physicochemical properties of thirdgeneration tetracyclines. Table S5. The antibacterial spectrum of the newly approved tetracyclines. Table S6. Pharmacokinetics parameters of modern tetracyclines.

Author Contributions: Conceptualisation, methodology, writing—review and editing, supervision, A.R.; writing—original draft preparation, visualisation, E.L.B. All authors have read and agreed to the published version of the manuscript.

Funding: This research received no external funding.

Conflicts of Interest: The authors declare no conflict of interest.

\section{References}

1. Moffa, M.; Brook, I. 26-Tetracyclines, Glycylcyclines, and Chloramphenicol. In Mandell, Douglas, and Bennett's Principles and Practice of Infectious Diseases, 8th ed.; Bennett, J.E., Dolin, R., Blaser, M.J., Eds.; W.B. Saunders: Philadelphia, PA, USA, 2015; pp. 2607-2618.e2, ISBN 9781455748013. [CrossRef]

2. Klein, N.C.; Cunha, B.A. Tetracyclines. Med. Clin. N. Am. 1995, 79, 789-801. [CrossRef]

3. Nelson, M.L.; Levy, S.B. The history of the tetracyclines. Ann. N. Y. Acad. Sci. 2011, 1241, 17-32. [CrossRef]

4. Duggar, B.M. Aureomycin; a product of the continuing search for new antibiotics. Ann. N. Y. Acad. Sci. 1948, 51, 177-181. [CrossRef]

5. Dubos, R.J.; Hotchkiss, R.D. The production of bactericidal substances by aerobic sporulating bacilli. J. Exp. Med. 1941, 73, 629-640. [CrossRef] [PubMed]

6. Waksman, S.A.; Schatz, A.; Reynolds, D.M. Production of antibiotic substances by actinomycetes. Ann. N. Y. Acad. Sci. 2010, 1213, 112-124. [CrossRef] [PubMed]

7. Finland, M. Twenty-fifth anniversary of the discovery of Aureomycin: The place of the tetracyclines in antimicrobial therapy. Clin. Pharmacol. Ther. 1974, 15, 3-8. [CrossRef] [PubMed]

8. Raistrick, H. Aureomycin, a New Antibiotic. Nature 1949, 163, 159-160. [CrossRef] [PubMed]

9. The Tetracyclines; Hlavka, J.J.; Boothe, J.H. (Eds.) Handbook of Experimental Pharmacology; Springer: Berlin/Heidelberg, Germany, 1985; ISBN 978-3-642-70306-5.

10. Griffin, M.O.; Fricovsky, E.; Ceballos, G.; Villarreal, F. Tetracyclines: A pleitropic family of compounds with promising therapeutic properties. Review of the literature. Am. J. Physiol. Physiol. 2010, 299, C539-C548. [CrossRef]

11. Lombardino, J.G. A brief history of pfizer central research. Bull. Hist. Chem. 2000, 25, 6.

12. Stephens, C.R.; Conover, L.H.; Hochstein, F.A.; Regna, P.P.; Pilgrim, F.J; Brunings, K.J.; Woodward, R.B. Terramycin. VIII. structure of aureomycin and terramycin. J. Am. Chem. Soc. 1952, 74, 4976-4977. [CrossRef]

13. Zhanel, G.G.; Homenuik, K.; Nichol, K.; Noreddin, A.; Vercaigne, L.; Embil, J.; Gin, A.; Karlowsky, J.A.; Hoban, D.J. The Glycylcyclines: A Comparative Review with the Tetracyclines. Drugs 2004, 64, 63-88. [CrossRef]

14. Rogalski, W. Chemical Modification of the Tetracyclines. In The Tetracyclines; Handbook of Experimental Pharmacology; Hlavka, J.J., Boothe, J.H., Eds.; Springer: Berlin/Heidelberg, Germany, 1985; pp. 179-316, ISBN 978-3-642-70304-1.

15. McCormick, J.R.D.; Sjolander, N.O.; Hirsch, U.; Jensen, E.R.; Doerschuk, A.P. A new family of antibiotics: The demethyltetracyclines. J. Am. Chem. Soc. 1957, 79, 4561-4563. [CrossRef]

16. NCATS Inxight Drugs-Methacycline. Available online: https://drugs.ncats.io/substance/IR235I7C5P (accessed on 29 October 2021).

17. Garrido-Mesa, N.; Zarzuelo, A.; Galvez, J. Minocycline: Far beyond an antibiotic. Br. J. Pharmacol. 2013, 169, 337-352. [CrossRef]

18. Grossman, T.H. Tetracycline Antibiotics and Resistance. Cold Spring Harb. Perspect. Med. 2016, 6, a025387. [CrossRef]

19. Lee, Y.R.; Burton, C.E. Eravacycline, a newly approved fluorocycline. Eur. J. Clin. Microbiol. Infect. Dis. 2019, 38, 1787-1794. [CrossRef]

20. Moore, A.Y.; Charles, J.E.M.; Moore, S. Sarecycline: A narrow spectrum tetracycline for the treatment of moderate-to-severe acne vulgaris. Futur. Microbiol. 2019, 14, 1235-1242. [CrossRef]

21. Fuoco, D. Classification Framework and Chemical Biology of Tetracycline-Structure-Based Drugs. Antibiotics 2012, 1, 1. [CrossRef] 
22. Villano, S.; Steenbergen, J.; Loh, E. Omadacycline: Development of a novel aminomethylcycline antibiotic for treating drugresistant bacterial infections. Futur. Microbiol. 2016, 11, 1421-1434. [CrossRef]

23. Giovanni, P.; Eugenio, C.; Giuseppe, M.; Brenner, M.; Lu, R.; Huang, S.; Armstrong, W.P.; Gajanan, J.; Seyedi, F.; Johnston, S. Process for Making Sarecycline Hydrochloride. U.S. Patent 17/043,017, 21 January 2021.

24. Ramachanderan, R.; Schaefer, B. Tetracycline antibiotics. ChemTexts 2021, 7, 1-42. [CrossRef]

25. Nelson, M.L.; Ismail, M.Y.; McIntyre, L.; Bhatia, B.; Viski, P.; Hawkins, P.; Rennie, G.; Andorsky, D.; Messersmith, D.; Stapleton, K.; et al. Versatile and Facile Synthesis of Diverse Semisynthetic Tetracycline Derivatives via Pd-Catalyzed Reactions. J. Org. Chem. 2003, 68, 5838-5851. [CrossRef]

26. Stein, G.E.; Babinchak, T. Tigecycline: An update. Diagn. Microbiol. Infect. Dis. 2013, 75, 331-336. [CrossRef]

27. Nguyen, F.; Starosta, A.L.; Arenz, S.; Sohmen, D.; Dönhöfer, A.; Wilson, D.N. Tetracycline antibiotics and resistance mechanisms. Biol. Chem. 2014, 395, 559-575. [CrossRef]

28. Doan, T.-L.; Fung, H.B.; Mehta, D.; Riska, P.F. Tigecycline: A glycylcycline antimicrobial agent. Clin. Ther. 2006, 28, 1079-1106. [CrossRef]

29. Greer, N.D. Tigecycline (Tygacil): The First in the Glycylcycline Class of Antibiotics. Bayl. Univ. Med. Cent. Proc. 2006, 19, 155-161. [CrossRef]

30. Olson, M.W.; Ruzin, A.; Feyfant, E.; Rush, T.S.; O'Connell, J.; Bradford, P.A. Functional, Biophysical, and Structural Bases for Antibacterial Activity of Tigecycline. Antimicrob. Agents Chemother. 2006, 50, 2156-2166. [CrossRef]

31. FDA. Drug Approval Package: Tygacil (Tigecycline) NDA \#021821. Available online: https://www.accessdata.fda.gov/ drugsatfda_docs/nda/2005/21-821_Tygacil.cfm (accessed on 4 October 2021).

32. EMA Tygacil. Available online: https://www.ema.europa.eu/en/medicines/human/EPAR/tygacil (accessed on 29 September 2021).

33. Babinchak, T.; Ellis-Grosse, E.; Dartois, N.; Rose, G.M.; Loh, E.; Tigecycline 301 Study Group; Tigecycline 306 Study Group. The Efficacy and Safety of Tigecycline for the Treatment of Complicated Intra-Abdominal Infections: Analysis of Pooled Clinical Trial Data. Clin. Infect. Dis. 2005, 41 (Suppl. S5), S354-S367. [CrossRef] [PubMed]

34. Breedt, J.; Teras, J.; Gardovskis, J.; Maritz, F.J.; Vaasna, T.; Ross, D.P.; Gioud-Paquet, M.; Dartois, N.; Ellis-Grosse, E.J.; Loh, E. Safety and Efficacy of Tigecycline in Treatment of Skin and Skin Structure Infections: Results of a Double-Blind Phase 3 Comparison Study with Vancomycin-Aztreonam. Antimicrob. Agents Chemother. 2005, 49, 4658-4666. [CrossRef]

35. Tanaseanu, C.; Bergallo, C.; Teglia, O.; Jasovich, A.; Oliva, M.E.; Dukart, G.; Dartois, N.; Cooper, C.A.; Gandjini, H.; Mallick, R. Integrated results of 2 phase 3 studies comparing tigecycline and levofloxacin in community-acquired pneumonia. Diagn. Microbiol. Infect. Dis. 2008, 61, 329-338. [CrossRef]

36. Falagas, M.E.; Metaxas, E.I. Tigecycline for the treatment of patients with community-acquired pneumonia requiring hospitalization. Expert Rev. Anti-Infect. Ther. 2009, 7, 913-923. [CrossRef]

37. Tigecycline I DrugBank Online. Available online: https://go.drugbank.com/drugs/DB00560 (accessed on 2 August 2021).

38. Zhanel, G.G.; Esquivel, J.; Zelenitsky, S.; Lawrence, C.K.; Adam, H.J.; Golden, A.; Hink, R.; Berry, L.; Schweizer, F.; Zhanel, M.A.; et al. Omadacycline: A Novel Oral and Intravenous Aminomethylcycline Antibiotic Agent. Drugs 2020, 80, 285-313. [CrossRef]

39. FDA Drug Approval Package: Nuzyra. Available online: https://www.accessdata.fda.gov/drugsatfda_docs/nda/2018/20981 6Orig1s000,209817Orig1s000TOC.cfm (accessed on 4 October 2021).

40. Zhanel, G.G.; Cheung, D.; Adam, H.; Zelenitsky, S.; Golden, A.; Schweizer, F.; Gorityala, B.; Lagacé-Wiens, P.R.S.; Walkty, A.; Gin, A.S.; et al. Review of Eravacycline, a Novel Fluorocycline Antibacterial Agent. Drugs 2016, 76, 567-588. [CrossRef] [PubMed]

41. Scott, L.J. Eravacycline: A Review in Complicated Intra-Abdominal Infections. Drugs 2019, 79, 315-324. [CrossRef]

42. Bunick, C.G.; Keri, J.; Tanaka, S.K.; Furey, N.; Damiani, G.; Johnson, J.L.; Grada, A. Antibacterial Mechanisms and Efficacy of Sarecycline in Animal Models of Infection and Inflammation. Antibiotics 2021, 10, 439. [CrossRef]

43. Haidari, W.; Bruinsma, R.; Cardenas-de La Garza, J.A.; Feldman, S.R. Sarecycline Review. Ann. Pharmacother. 2019, 54, 164-170. [CrossRef]

44. Deeks, E.D. Sarecycline: First Global Approval. Drugs 2019, 79, 325-329. [CrossRef]

45. Kaul, G.; Saxena, D.; Dasgupta, A.; Chopra, S. Sarecycline hydrochloride for the treatment of acne vulgaris. Drugs Today 2019, 55, 615-625. [CrossRef]

46. FDA. Drug Approval Package: Seysara (Sarecycline). Available online: https://www.accessdata.fda.gov/drugsatfda_docs/nda/ 2018/209521Orig1s000TOC.cfm (accessed on 7 October 2021).

47. Systèmes, D. BIOVIA Draw for Academics. Available online: https://discover.3ds.com/biovia-draw-academic (accessed on 6 July 2021).

48. Bahrami, F.; Morris, D.L.; Pourgholami, M.H. Tetracyclines: Drugs with Huge Therapeutic Potential. Mini-Rev. Med. Chem. 2012, 12, 44-52. [CrossRef]

49. Rizvi, S.F.A.; Tariq, S.; Anwar, U. Tetracycline: Classification, Structure Activity Relationship and Mechanism of Action as a Theranostic Agent for Infectious Lesions-A Mini Review. Biomed. J. Sci. Tech. Res. 2018, 7, 001-010. [CrossRef]

50. Heinemann, F.W.; Leypold, C.F.; Roman, C.R.; Schmitt, M.O.; Schneider, S. X-Ray Crystallography of Tetracycline, Doxycycline and Sancycline. J. Chem. Crystallogr. 2013, 43, 213-222. [CrossRef] 
51. Honeyman, L.; Ismail, M.; Nelson, M.L.; Bhatia, B.; Bowser, T.E.; Chen, J.; Mechiche, R.; Ohemeng, K.; Verma, A.K.; Cannon, E.P.; et al. Structure-Activity Relationship of the Aminomethylcyclines and the Discovery of Omadacycline. Antimicrob. Agents Chemother. 2015, 59, 7044-7053. [CrossRef]

52. Zhanel, G.G.; Karlowsky, J.A.; Rubinstein, E.; Hoban, D.J. Tigecycline: A novel glycylcycline antibiotic. Expert Rev. Anti-Infect. Ther. 2006, 4, 9-25. [CrossRef]

53. Omadacycline. Available online: https://go.drugbank.com/drugs/DB12455 (accessed on 7 October 2021).

54. PubChem Omadacycline. Available online: https://pubchem.ncbi.nlm.nih.gov/compound/54697325 (accessed on 5 October 2021).

55. European Medicines Agency Xerava. Available online: https://www.ema.europa.eu/en/medicines/human/EPAR/xerava (accessed on 3 August 2021).

56. PubChem Sarecycline. Available online: https:// pubchem.ncbi.nlm.nih.gov/compound/54681908 (accessed on 4 October 2021).

57. Batool, Z.; Lomakin, I.B.; Polikanov, Y.S.; Bunick, C.G. Sarecycline interferes with tRNA accommodation and tethers mRNA to the $70 S$ ribosome. Proc. Natl. Acad. Sci. USA 2020, 117, 20530-20537. [CrossRef]

58. John, M.; Beale, J.H.B. Wilson and Giswold's Organic Medicinal and Pharmaceutical Chemistry, 12th ed.; Lippincott Williams \& Wilkins, Wolters Kluwer Health: Baltimore, MD, USA, 2011; pp. 301-307.

59. Bayliss, M.A.J.; Rigdova, K.; Kyriakides, M.; Grier, S.; Lovering, A.M.; Ellery, K.; Griffith, D.C.; MacGowan, A. Challenges in the bioanalysis of tetracyclines: Epimerisation and chelation with metals. J. Chromatogr. B 2019, 1134-1135, 121807. [CrossRef]

60. Pulicharla, R.; Hegde, K.; Brar, S.K.; Surampalli, R.Y. Tetracyclines metal complexation: Significance and fate of mutual existence in the environment. Environ. Pollut. 2017, 221, 1-14. [CrossRef]

61. Sanli, S.; Şanli, N.; Alsancak, G. Determination of Protonation Constants of Some Tetracycline Antibiotics by Potentiometry and Lc Methods in Water and Acetonitrile-Water Binary Mixtures. J. Braz. Chem. Soc. 2009, 20, 939-946. [CrossRef]

62. Zhao, Y.; Geng, J.; Wang, X.; Gu, X.; Gao, S. Tetracycline adsorption on kaolinite: pH, metal cations and humic acid effects. Ecotoxicology 2011, 20, 1141-1147. [CrossRef]

63. Schmitt, M.O.; Schneider, S. Novel Insight into the Protonation-Deprotonation Equilibria of Tetracycline, Sancycline and 10Propoxy-Sancycline in Aqueous Solution. I. Analysis of the $\mathrm{pH}$-Dependent UV/vis Absorption Spectra by the SVD Technique. Z. Phys. Chem. 2006, 220, 441-475. [CrossRef]

64. Jin, L.; Amaya-Mazo, X.; Apel, M.E.; Sankisa, S.S.; Johnson, E.; Zbyszynska, M.A.; Han, A. Ca2+ and Mg2+ bind tetracycline with distinct stoichiometries and linked deprotonation. Biophys. Chem. 2007, 128, 185-196. [CrossRef]

65. Arias, K.; Robinson, S.G.; Lyngaas, S.S.; Cherala, S.S.; Hartzell, M.; Mei, S.; Vilic, A.; Girel, J.K.; Kuemmell, A.; Vrettos, J.S.; et al. Minocycline and tigecycline form higher-order Ca2+ complexes of stronger affinity than tetracycline. Inorg. Chim. Acta 2016, 441, 181-191. [CrossRef]

66. Marvin / ChemAxon. Available online: https:/ / chemaxon.com/products/marvin (accessed on 11 October 2021).

67. Tu, Y.-P. Dissociative protonation and long-range proton migration: The chemistry of singly- and doubly-protonated tigecycline. Int. J. Mass Spectrom. 2018, 434, 164-171. [CrossRef]

68. Grenier, D.; Huot, M.-P.; Mayrand, D. Iron-Chelating Activity of Tetracyclines and Its Impact on the Susceptibility of Actinobacillus actinomycetemcomitans to These Antibiotics. Antimicrob. Agents Chemother. 2000, 44, 763-766. [CrossRef]

69. Guerra, W.; Silva-Caldeira, P.P.; Terenzi, H.; Pereira-Maia, E.C. Impact of metal coordination on the antibiotic and non-antibiotic activities of tetracycline-based drugs. Coord. Chem. Rev. 2016, 327-328, 188-199. [CrossRef]

70. Rocha, D.P.; Pinto, G.F.; Ruggiero, R.; De Oliveira, C.A.; Guerra, W.; Fontes, A.P.S.; Tavares, T.T.; Marzano, I.M.; Pereira-Maia, E.C. Coordenação de metais a antibióticos como uma estratégia de combate à resistência bacteriana. Quím. Nova 2011, 34, 111-118. [CrossRef]

71. Wilson and Gisvold's Textbook of Organic Medicinal and Pharmaceutical Chemistry, 12th ed.; Beale, J.M., Jr.; Block, J.H. (Eds.) Wolters Kluwer Health: Baltimore, MD, USA, 2010; ISBN 978-0-7817-7929-6.

72. Sum, P.-E.; Petersen, P. Synthesis and structure-activity relationship of novel glycylcycline derivatives leading to the discovery of GAR-936. Bioorg. Med. Chem. Lett. 1999, 9, 1459-1462. [CrossRef]

73. Kaewpoowat, Q.; Ostrosky-Zeichner, L. Tigecycline: A critical safety review. Expert Opin. Drug Saf. 2014, 14, 335-342. [CrossRef]

74. Jenner, L.; Starosta, A.L.; Terry, D.S.; Mikolajka, A.; Filonava, L.; Yusupov, M.; Blanchard, S.C.; Wilson, D.N.; Yusupova, G. Structural basis for potent inhibitory activity of the antibiotic tigecycline during protein synthesis. Proc. Natl. Acad. Sci. USA 2013, 110, 3812-3816. [CrossRef]

75. Chopra, I.; Roberts, M. Tetracycline Antibiotics: Mode of Action, Applications, Molecular Biology, and Epidemiology of Bacterial Resistance. Microbiol. Mol. Biol. Rev. 2001, 65, 232-260. [CrossRef]

76. Bronson, J.; Barrett, J.F. Quinolone, Everninomycin, Glycylcycline, Carbapenem, Lipopeptide and Cephem Antibacterials in Clinical Development. Curr. Med. Chem. 2001, 8, 1775-1793. [CrossRef] [PubMed]

77. Tanaka, S.K.; Steenbergen, J.; Villano, S. Discovery, pharmacology, and clinical profile of omadacycline, a novel aminomethylcycline antibiotic. Bioorg. Med. Chem. 2016, 24, 6409-6419. [CrossRef]

78. Burgos, R.M.; Rodvold, K.A. Omadacycline: A novel aminomethylcycline. Infect. Drug Resist. 2019, 12, 1895-1915. [CrossRef]

79. Xiao, X.-Y.; Hunt, D.K.; Zhou, J.; Clark, R.B.; Dunwoody, N.; Fyfe, C.; Grossman, T.H.; O’Brien, W.J.; Plamondon, L.; Rönn, M.; et al. Fluorocyclines. 1. 7-Fluoro-9-pyrrolidinoacetamido-6-demethyl-6-deoxytetracycline: A Potent, Broad Spectrum Antibacterial Agent. J. Med. Chem. 2012, 55, 597-605. [CrossRef] 
80. Clark, R.B.; Hunt, D.K.; He, M.; Achorn, C.; Chen, C.-L.; Deng, Y.; Fyfe, C.; Grossman, T.H.; Hogan, P.C.; O’Brien, W.J.; et al. Fluorocyclines. 2. Optimization of the C-9 Side-Chain for Antibacterial Activity and Oral Efficacy. J. Med. Chem. 2012, 55, 606-622. [CrossRef] [PubMed]

81. Brodersen, D.E.; Clemons, W.M.; Carter, A.P.; Morgan-Warren, R.J.; Wimberly, B.T.; Ramakrishnan, V. The Structural Basis for the Action of the Antibiotics Tetracycline, Pactamycin, and Hygromycin B on the 30S Ribosomal Subunit. Cell 2000, 103, 1143-1154 [CrossRef]

82. Maxwell, I.H. Partial removal of bound transfer RNA from polysomes engaged in protein synthesis in vitro after addition of tetracycline. Biochim. Biophys. Acta (BBA) Nucleic Acids Protein Synth. 1967, 138, 337-346. [CrossRef]

83. Tessier, P.R.; Nicolau, D.P. Tigecycline DisplaysIn VivoBactericidal Activity against Extended-Spectrum- $\beta$-Lactamase-Producing Enterobacteriaceae after 72-Hour Exposure Period. Antimicrob. Agents Chemother. 2012, 57, 640-642. [CrossRef] [PubMed]

84. BioRender. Available online: https:/ / biorender.com/ (accessed on 30 September 2021).

85. Thaker, M.; Spanogiannopoulos, P.; Wright, G.D. The tetracycline resistome. Cell. Mol. Life Sci. 2009, 67, 419-431. [CrossRef] [PubMed]

86. Schnappinger, D.; Hillen, W. Tetracyclines: Antibiotic action, uptake, and resistance mechanisms. Arch. Microbiol. 1996, 165, 359-369. [CrossRef]

87. Peterson, L.R. A review of tigecycline-The first glycylcycline. Int. J. Antimicrob. Agents 2008, 32, S215-S222. [CrossRef]

88. Pankey, G.A. Tigecycline. J. Antimicrob. Chemother. 2005, 56, 470-480. [CrossRef]

89. Projan, S.J. Preclinical Pharmacology of GAR-936, a Novel Glycylcycline Antibacterial Agent. Pharmacother. J. Hum. Pharmacol. Drug Ther. 2000, 20, 219S-223S; discussion 224S-228S. [CrossRef] [PubMed]

90. Hirata, T.; Saito, A.; Nishino, K.; Tamura, N.; Yamaguchi, A. Effects of Efflux Transporter Genes on Susceptibility of Escherichia coli to Tigecycline (GAR-936). Antimicrob. Agents Chemother. 2004, 48, 2179-2184. [CrossRef]

91. Macone, A.B.; Caruso, B.K.; Leahy, R.G.; Donatelli, J.; Weir, S.; Draper, M.P.; Tanaka, S.K.; Levy, S.B. In VitroandIn VivoAntibacterial Activities of Omadacycline, a Novel Aminomethylcycline. Antimicrob. Agents Chemother. 2013, 58, 1127-1135. [CrossRef] [PubMed]

92. Heaney, M.; Mahoney, M.V.; Gallagher, J.C. Eravacycline: The Tetracyclines Strike Back. Ann. Pharmacother. 2019, 53, 1124-1135. [CrossRef]

93. Grossman, T.H.; Starosta, A.L.; Fyfe, C.; O’Brien, W.; Rothstein, D.M.; Mikolajka, A.; Wilson, D.N.; Sutcliffe, J.A. Target- and Resistance-Based Mechanistic Studies with TP-434, a Novel Fluorocycline Antibiotic. Antimicrob. Agents Chemother. 2012, 56, 2559-2564. [CrossRef] [PubMed]

94. Farrah, G.; Tan, E. The use of oral antibiotics in treating acne vulgaris: A new approach. Dermatol. Ther. 2016, 29, 377-384. [CrossRef]

95. Mays, R.M.; Gordon, R.A.; Wilson, J.M.; Silapunt, S. New antibiotic therapies for acne and rosacea. Dermatol. Ther. 2012, $25,23-37$. [CrossRef] [PubMed]

96. Perret, L.J.; Tait, C.P. Non-antibiotic properties of tetracyclines and their clinical application in dermatology. Australas. J. Dermatol. 2013, 55, 111-118. [CrossRef]

97. Rosso, J.Q.; Draelos, Z.D.; Effron, C.; Kircik, L.H. Oral Sarecycline for Treatment of Papulopustular Rosacea: Results of a Pilot Study of Effectiveness and Safety. J. Drugs Dermatol. 2021, 20, 426-431. [CrossRef] [PubMed]

98. Sapadin, A.N.; Fleischmajer, R. Tetracyclines: Nonantibiotic properties and their clinical implications. J. Am. Acad. Dermatol. 2006, 54, 258-265. [CrossRef]

99. Esterly, N.B.; Koransky, J.S.; Furey, N.L.; Trevisan, M. Neutrophil chemotaxis in patients with acne receiving oral tetracycline therapy. Arch. Dermatol. 1984, 120, 1308-1313. [CrossRef]

100. Skidmore, R.; Kovach, R.; Walker, C.; Thomas, J.; Bradshaw, M.; Leyden, J.; Powala, C.; Ashley, R. Effects of Subantimicrobial-Dose Doxycycline in the Treatment of Moderate Acne. Arch. Dermatol. 2003, 139, 459-464. [CrossRef] [PubMed]

101. Tilley, B.C.; Alarcón, G.S.; Heyse, S.P.; Trentham, D.E.; Neuner, R.; Kaplan, D.A.; Clegg, D.O.; Leisen, J.C.C.; Buckley, L.; Cooper, S.M.; et al. Minocycline in Rheumatoid Arthritis: A 48-Week, Double-Blind, Placebo-Controlled Trial. Ann. Intern. Med. 1995, 122, 81-89. [CrossRef]

102. O’Dell, J.R.; Elliott, J.R.; Mallek, J.A.; Mikuls, T.R.; Weaver, C.A.; Glickstein, S.; Blakely, K.M.; Hausch, R.; Leff, R.D. Treatment of early seropositive rheumatoid arthritis: Doxycycline plus methotrexate versus methotrexate alone. Arthritis Rheum. 2006, 54, 621-627. [CrossRef]

103. Macdonald, A.; Feiwel, M. Perioral dermatitis: Aetiology and treatment with tetracycline. Br. J. Dermatol. 1972, 87, 315-319. [CrossRef]

104. Jansen, T.; Plewig, G. Rosacea: Classification and Treatment. J. R. Soc. Med. 1997, 90, 144-150. [CrossRef]

105. Le, C.H.; Morales, A.; Trentham, D.E. Minocycline in early diffuse scleroderma. Lancet 1998, 352, 1755-1756. [CrossRef]

106. Chaidemenos, G.C. Tetracycline and niacinamide in the treatment of blistering skin diseases. Clin. Dermatol. 2001, 19, 781-785. [CrossRef]

107. Lokeshwar, B.L.; Selzer, M.G.; Zhu, B.-Q.; Block, N.L.; Golub, L.M. Inhibition of cell proliferation, invasion, tumor growth and metastasis by an oral non-antimicrobial tetracycline analog (COL-3) in a metastatic prostate cancer model. Int. J. Cancer 2001, 98, 297-309. [CrossRef] [PubMed] 
108. Cianfrocca, M.; Cooley, T.P.; Lee, J.Y.; Rudek, M.A.; Scadden, D.T.; Ratner, L.; Pluda, J.M.; Figg, W.D.; Krown, S.E.; Dezube, B.J. Matrix Metalloproteinase Inhibitor COL-3 in the Treatment of AIDS-Related Kaposi's Sarcoma: A Phase I AIDS Malignancy Consortium Study. J. Clin. Oncol. 2002, 20, 153-159. [CrossRef]

109. Mosorin, M.; Juvonen, J.; Biancari, F.; Satta, J.; Surcel, H.-M.; Leinonen, M.; Saikku, P.; Juvonen, T. Use of doxycycline to decrease the growth rate of abdominal aortic aneurysms: A randomized, double-blind, placebo-controlled pilot study. J. Vasc. Surg. 2001, 34, 606-610. [CrossRef]

110. Bachelez, H.; Senet, P.; Cadranel, J.; Kaoukhov, A.; Dubertret, L. The Use of Tetracyclines for the Treatment of Sarcoidosis. Arch. Dermatol. 2001, 137, 69-73. [CrossRef]

111. Takeshita, S.; Ono, Y.; Kozuma, K.; Suzuki, M.; Kawamura, Y.; Yokoyama, N.; Furukawa, T.; Isshiki, T. Modulation of oxidative burst of neutrophils by doxycycline in patients with acute myocardial infarction. J. Antimicrob. Chemother. 2002, 49, 411-413. [CrossRef]

112. Mrcp, J.B.-J.; Tan, S.V.; Graham-Brown, R.A.C.; Pembroke, A.C. The successful use of minocycline in pyoderma gangrenosum-A report of seven cases and review of the literature. J. Dermatol. Treat. 1989, 1, 23-25. [CrossRef]

113. Wennström, J.L.; Newman, H.N.; MacNeill, S.R.; Killoy, W.J.; Griffiths, G.S.; Gillam, D.G.; Krok, L.; Needleman, I.G.; Weiss, G.; Garrett, S. Utilisation of locally delivered doxycycline in non-surgical treatment of chronic periodontitis. A Comparative Multi-Centre Trial of 2 Treatment Approaches. J. Clin. Periodontol. 2001, 28, 753-761. [CrossRef] [PubMed]

114. Jemec, G.B.; Wendelboe, P. Topical clindamycin versus systemic tetracycline in the treatment of hidradenitis suppurativa. J. Am. Acad. Dermatol. 1998, 39, 971-974. [CrossRef]

115. Joshi, R.K.; Atukorala, D.N.; Abanmi, A.; Al Khamis, O.; Haleem, A. Successful treatment of Sweet's syndrome with doxycycline. Br. J. Dermatol. 1993, 128, 584-586. [CrossRef]

116. Humbert, P.; Faivre, B.; Gibey, R.; Agache, P. Use of anti-collagenase properties of doxycycline in treatment of alpha 1-antitrypsin deficiency panniculitis. Acta Derm. Venereol. 1991, 71, 189-194.

117. Piamphongsant, T. Tetracycline for the treatment of pityriasis lichenoides. Br. J. Dermatol. 1974, 91, 319-322. [CrossRef]

118. Da Silva, L.M.; Salgado, H.R.N. Tigecycline: A Review of Properties, Applications, and Analytical Methods. Ther. Drug Monit. 2010, 32, 282-288. [CrossRef]

119. Pillar, C.M.; Draghi, D.C.; Dowzicky, M.J.; Sahm, D.F. In Vitro Activity of Tigecycline against Gram-Positive and Gram-Negative Pathogens as Evaluated by Broth Microdilution and Etest. J. Clin. Microbiol. 2008, 46, 2862-2867. [CrossRef]

120. Noskin, G.A. Tigecycline: A New Glycylcycline for Treatment of Serious Infections. Clin. Infect. Dis. 2005, 41, S303-S314. [CrossRef]

121. Petersen, P.J.; Jacobus, N.V.; Weiss, W.J.; Sum, P.E.; Testa, R.T. In Vitro and In Vivo Antibacterial Activities of a Novel Glycylcycline, the 9- $t$-Butylglycylamido Derivative of Minocycline (GAR-936). Antimicrob. Agents Chemother. 1999, 43, 738-744. [CrossRef]

122. Karlowsky, J.A.; Steenbergen, J.; Zhanel, G.G. Microbiology and Preclinical Review of Omadacycline. Clin. Infect. Dis. 2019, 69, S6-S15. [CrossRef]

123. Pfaller, M.A.; Rhomberg, P.R.; Huband, M.D.; Flamm, R.K. Activities of Omadacycline and Comparator Agents against Staphylococcus aureus Isolates from a Surveillance Program Conducted in North America and Europe. Antimicrob. Agents Chemother. 2017, 61, e02411-16. [CrossRef] [PubMed]

124. Goldstein, E.J.C.; Citron, D.M.; Tyrrell, K.L.; Leoncio, E.; Merriam, C.V. Comparative In Vitro Activity of Omadacycline against Dog and Cat Bite Wound Isolates. Antimicrob. Agents Chemother. 2018, 62, e02551-17. [CrossRef] [PubMed]

125. Antimicrobial Drugs Advisory Committee (AMDAC) Briefing Book. Omadacycline P-Toluenesulfonate Tablets and Injection. Available online: https:/ / www.fda.gov / media/115100/download (accessed on 10 June 2021).

126. Zhanel, G.; Critchley, I.; Lin, L.-Y.; Alvandi, N. Microbiological Profile of Sarecycline, a Novel Targeted Spectrum Tetracycline for the Treatment of Acne Vulgaris. Antimicrob. Agents Chemother. 2019, 63, e01297-18. [CrossRef] [PubMed]

127. Thompson, K.G.; Rainer, B.M.; Antonescu, C.; Florea, L.; Mongodin, E.F.; Kang, S.; Chien, A.L. Minocycline and Its Impact on Microbial Dysbiosis in the Skin and Gastrointestinal Tract of Acne Patients. Ann. Dermatol. 2020, 32, 21-30. [CrossRef]

128. Graber, E.M. Treating acne with the tetracycline class of antibiotics: A review. Dermatol. Rev. 2021, 1-10. [CrossRef]

129. Chopra, I. Glycylcyclines: Third-generation tetracycline antibiotics. Curr. Opin. Pharmacol. 2001, 1, 464-469. [CrossRef]

130. Draper, M.P.; Weir, S.; Macone, A.; Donatelli, J.; Trieber, C.A.; Tanaka, S.K.; Levy, S.B. Mechanism of Action of the Novel Aminomethylcycline Antibiotic Omadacycline. Antimicrob. Agents Chemother. 2013, 58, 1279-1283. [CrossRef]

131. Kobayashi, T.; Nonaka, L.; Maruyama, F.; Suzuki, S. Molecular Evidence for the Ancient Origin of the Ribosomal Protection Protein That Mediates Tetracycline Resistance in Bacteria. J. Mol. Evol. 2007, 65, 228-235. [CrossRef]

132. Yang, W.; Moore, I.F.; Koteva, K.P.; Bareich, D.C.; Hughes, D.W.; Wright, G.D. TetX Is a Flavin-dependent Monooxygenase Conferring Resistance to Tetracycline Antibiotics. J. Biol. Chem. 2004, 279, 52346-52352. [CrossRef] [PubMed]

133. Dougherty, J.A.; Sucher, A.J.; Chahine, E.B.; Shihadeh, K.C. Omadacycline: A New Tetracycline Antibiotic. Ann. Pharmacother 2018, 53, 486-500. [CrossRef] [PubMed]

134. Dean, C.R.; Visalli, M.A.; Projan, S.J.; Sum, P.-E.; Bradford, P.A. Efflux-Mediated Resistance to Tigecycline (GAR-936) in Pseudomonas aeruginosa PAO1. Antimicrob. Agents Chemother. 2003, 47, 972-978. [CrossRef] [PubMed]

135. Visalli, M.A.; Murphy, E.; Projan, S.J.; Bradford, P.A. AcrAB Multidrug Efflux Pump Is Associated with Reduced Levels of Susceptibility to Tigecycline (GAR-936) in Proteus mirabilis. Antimicrob. Agents Chemother. 2003, 47, 665-669. [CrossRef] 
136. Peleg, A.Y.; Adams, J.; Paterson, D.L. Tigecycline Efflux as a Mechanism for Nonsusceptibility in Acinetobacter baumannii. Antimicrob. Agents Chemother. 2007, 51, 2065-2069. [CrossRef]

137. Damier-Piolle, L.; Magnet, S.; Breémont, S.; Lambert, T.; Courvalin, P. AdeIJK, a Resistance-Nodulation-Cell Division Pump Effluxing Multiple Antibiotics in Acinetobacter baumannii. Antimicrob. Agents Chemother. 2008, 52, 557-562. [CrossRef] [PubMed]

138. McAleese, F.; Petersen, P.; Ruzin, A.; Dunman, P.M.; Murphy, E.; Projan, S.J.; Bradford, P.A. A Novel MATE Family Efflux Pump Contributes to the Reduced Susceptibility of Laboratory-Derived Staphylococcus aureus Mutants to Tigecycline. Antimicrob. Agents Chemother. 2005, 49, 1865-1871. [CrossRef]

139. Beabout, K.; Hammerstrom, T.G.; Perez, A.M.; Magalhaes, B.D.F.; Prater, A.G.; Clements, T.P.; Arias, C.A.; Saxer, G.; Shamoo, Y. The Ribosomal S10 Protein Is a General Target for Decreased Tigecycline Susceptibility. Antimicrob. Agents Chemother. 2015, 59, 5561-5566. [CrossRef]

140. Moore, I.F.; Hughes, D.W.; Wright, G.D. Tigecycline Is Modified by the Flavin-Dependent Monooxygenase TetX. Biochemistry 2005, 44, 11829-11835. [CrossRef]

141. He, T.; Wang, R.; Liu, D.; Walsh, T.R.; Zhang, R.; Lv, Y.; Ke, Y.; Ji, Q.; Wei, R.; Liu, Z.; et al. Emergence of plasmid-mediated high-level tigecycline resistance genes in animals and humans. Nat. Microbiol. 2019, 4, 1450-1456. [CrossRef]

142. Wang, L.; Liu, D.; Lv, Y.; Cui, L.; Li, Y.; Li, T.; Song, H.; Hao, Y.; Shen, J.; Wang, Y.; et al. Novel Plasmid-Mediated tet (X5) Gene Conferring Resistance to Tigecycline, Eravacycline, and Omadacycline in a Clinical Acinetobacter baumannii Isolate. Antimicrob. Agents Chemother. 2019, 64, e01326-19. [CrossRef]

143. Roberts, M.C. Update on acquired tetracycline resistance genes. FEMS Microbiol. Lett. 2005, 245, 195-203. [CrossRef]

144. Heidrich, C.G.; Mitova, S.; Schedlbauer, A.; Connell, S.R.; Fucini, P.; Steenbergen, J.N.; Berens, C. The Novel Aminomethylcycline Omadacycline Has High Specificity for the Primary Tetracycline-Binding Site on the Bacterial Ribosome. Antibiotics $2016,5,32$. [CrossRef]

145. XERAVA (Eravacycline) for Injection. Available online: https://www.accessdata.fda.gov/drugsatfda_docs/label/2018/21110 9lbl.pdf (accessed on 6 June 2021).

146. Alosaimy, S.; Abdul-Mutakabbir, J.C.; Kebriaei, R.; Jorgensen, S.C.J.; Rybak, M.J. Evaluation of Eravacycline: A Novel Fluorocycline. Pharmacother. J. Hum. Pharmacol. Drug Ther. 2020, 40, 221-238. [CrossRef]

147. Abdallah, M.; Olafisoye, O.; Cortes, C.; Urban, C.; Landman, D.; Quale, J. Activity of Eravacycline against Enterobacteriaceae and Acinetobacter baumannii, Including Multidrug-Resistant Isolates, from New York City. Antimicrob. Agents Chemother. 2014, 59, 1802-1805. [CrossRef]

148. Robertsen, H.L.; Musiol-Kroll, E.M. Actinomycete-Derived Polyketides as a Source of Antibiotics and Lead Structures for the Development of New Antimicrobial Drugs. Antibiotics 2019, 8, 157. [CrossRef]

149. Postier, R.G.; Green, S.L.; Klein, S.R.; Ellis-Grosse, E.J.; Loh, E.; Tigecycline 200 Study Group. Results of a multicenter, randomized, open-label efficacy and safety study of two doses of tigecycline for complicated skin and skin-structure infections in hospitalized patients. Clin. Ther. 2004, 26, 704-714. [CrossRef]

150. Li, L.; Hassan, K.A.; Tetu, S.G.; Naidu, V.; Pokhrel, A.; Cain, A.K.; Paulsen, I.T. The Transcriptomic Signature of Tigecycline in Acinetobacter baumannii. Front. Microbiol. 2020, 11, 565438. [CrossRef]

151. Durães, F.; Sousa, M.E. Omadacycline: A Newly Approved Antibacterial from the Class of Tetracyclines. Pharmaceuticals 2019, 12, 63. [CrossRef]

152. Stets, R.; Popescu, M.; Gonong, J.R.; Mitha, I.; Nseir, W.; Madej, A.; Kirsch, C.; Das, A.F.; Garrity-Ryan, L.; Steenbergen, J.N.; et al. Omadacycline for Community-Acquired Bacterial Pneumonia. N. Engl. J. Med. 2019, 380, 517-527. [CrossRef]

153. O’Riordan, W.; Green, S.; Overcash, J.S.; Puljiz, I.; Metallidis, S.; Gardovskis, J.; Garrity-Ryan, L.; Das, A.F.; Tzanis, E.; Eckburg, P.B.; et al. Omadacycline for Acute Bacterial Skin and Skin-Structure Infections. N. Engl. J. Med. 2019, 380, 528-538. [CrossRef]

154. Moore, A.Y.; Del Rosso, J.; Johnson, J.L.; Grada, A. Sarecycline: A Review of Preclinical and Clinical Evidence. Clin. Cosmet. Investig. Dermatol. 2020, 13, 553-560. [CrossRef]

155. Pariser, D.M.; Green, L.J.; Lain, E.L.; Schmitz, C.; Chinigo, A.S.; McNamee, B.; Berk, D.R. Safety and Tolerability of Sarecycline for the Treatment of Acne Vulgaris: Results from a Phase III, Multicenter, Open-Label Study and a Phase I Phototoxicity Study. J. Clin. Aesthet. Dermatol. 2019, 12, E53-E62. [CrossRef]

156. Muralidharan, G.; Micalizzi, M.; Speth, J.; Raible, D.; Troy, S. Pharmacokinetics of Tigecycline after Single and Multiple Doses in Healthy Subjects. Antimicrob. Agents Chemother. 2005, 49, 220-229. [CrossRef]

157. Markham, A.; Keam, S.J. Omadacycline: First Global Approval. Drugs 2018, 78, 1931-1937. [CrossRef]

158. FDA Drug Approval Package: XERAVA (Eravacycline). Available online: https://www.accessdata.fda.gov/drugsatfda_docs/ nda/2018/211109Orig1s000TOC.cfm (accessed on 30 November 2021).

159. Shutter, M.C.; Akhondi, H. Tetracycline. In StatPearls; StatPearls Publishing: Treasure Island, FL, USA, 2021.

160. Overcash, J.S.; Bhiwandi, P.; Garrity-Ryan, L.; Steenbergen, J.; Bai, S.; Chitra, S.; Manley, A.; Tzanis, E. Pharmacokinetics, Safety, and Clinical Outcomes of Omadacycline in Women with Cystitis: Results from a Phase 1b Study. Antimicrob. Agents Chemother. 2019, 63, e02083-18. [CrossRef] [PubMed]

161. Efimova, E.; Olesky, M.; Izmailyan, S.; Tsai, L. 1976. Pooled Analysis of Safety Data from Phases 2 and 3 Clinical Trials Evaluating Eravacycline in Complicated Intra-Abdominal Infections. Open Forum Infect. Dis. 2018, 5, S573-S574. [CrossRef]

162. Moore, T.J.; Zhang, H.; Anderson, G.; Alexander, G.C. Estimated Costs of Pivotal Trials for Novel Therapeutic Agents Approved by the US Food and Drug Administration, 2015-2016. JAMA Intern. Med. 2018, 178, 1451-1457. [CrossRef] 
163. Solomkin, J.S.; Ramesh, M.K.; Cesnauskas, G.; Novikovs, N.; Stefanova, P.; Sutcliffe, J.A.; Walpole, S.M.; Horn, P.T. Phase 2, Randomized, Double-Blind Study of the Efficacy and Safety of Two Dose Regimens of Eravacycline versus Ertapenem for Adult Community-Acquired Complicated Intra-Abdominal Infections. Antimicrob. Agents Chemother. 2014, 58, 1847-1854. [CrossRef]

164. Moore, A.; Green, L.J.; Bruce, S.; Sadick, N.; Tschen, E.; Werschler, P.; Cook-Bolden, F.E.; Dhawan, S.S.; Forsha, D.; Gold, M.H.; et al. Once-Daily Oral Sarecycline $1.5 \mathrm{mg} / \mathrm{kg} /$ day Is Effective for Moderate to Severe Acne Vulgaris: Results from Two Identically Designed, Phase 3, Randomized, Double-Blind Clinical Trials. J. Drugs Dermatol. 2018, 17, 987-996. [CrossRef]

165. Witkop, C.J., Jr.; Wolf, R.O. Hypoplasia and Intrinsic Staining of Enamel Following Tetracycline Therapy. JAMA 1963, 185, 1008-1011. [CrossRef]

166. Kadoyama, K.; Sakaeda, T.; Tamon, A.; Okuno, Y. Adverse Event Profile of Tigecycline: Data Mining of the Public Version of the U.S. Food and Drug Administration Adverse Event Reporting System. Biol. Pharm. Bull. 2012, 35, 967-970. [CrossRef]

167. Marot, J.-C.; Jonckheere, S.; Munyentwali, H.; Belkhir, L.; Vandercam, B.; Yombi, J.C. Tigecycline-induced acute pancreatitis: About two cases and review of the literature. Acta Clin. Belg. 2012, 67, 229-232. [CrossRef]

168. Berg, J.K.; Tzanis, E.; Garrity-Ryan, L.; Bai, S.; Chitra, S.; Manley, A.; Villano, S. Pharmacokinetics and Safety of Omadacycline in Subjects with Impaired Renal Function. Antimicrob. Agents Chemother. 2018, 62, e02057-17. [CrossRef]

169. Korth-Bradley, J.M.; McGovern, P.C.; Salageanu, J.; Matschke, K.; Plotka, A.; Pawlak, S. Tigecycline Does Not Prolong Corrected QT Intervals in Healthy Subjects. Antimicrob. Agents Chemother. 2013, 57, 1895-1901. [CrossRef]

170. Yahav, D.; Lador, A.; Paul, M.; Leibovici, L. Efficacy and safety of tigecycline: A systematic review and meta-analysis. J. Antimicrob. Chemother. 2011, 66, 1963-1971. [CrossRef]

171. FDA Drug Safety Communication: Increased Risk of Death with Tygacil (Tigecycline) Compared to Other Antibiotics Used to Treat Similar Infections. Available online: https://www.fda.gov/drugs/drug-safety-and-availability/fda-drug-safetycommunication-increased-risk-death-tygacil-tigecycline-compared-other-antibiotics (accessed on 22 October 2021).

172. Cai, Y.; Wang, R.; Liang, B.; Bai, N.; Liu, Y. Systematic Review and Meta-Analysis of the Effectiveness and Safety of Tigecycline for Treatment of Infectious Disease. Antimicrob. Agents Chemother. 2011, 55, 1162-1172. [CrossRef]

173. Tasina, E.; Haidich, A.-B.; Kokkali, S.; Arvanitidou, M. Efficacy and safety of tigecycline for the treatment of infectious diseases: A meta-analysis. Lancet Infect. Dis. 2011, 11, 834-844. [CrossRef]

174. Prasad, P.; Sun, J.; Danner, R.L.; Natanson, C. Excess Deaths Associated with Tigecycline After Approval Based on Noninferiority Trials. Clin. Infect. Dis. 2012, 54, 1699-1709. [CrossRef]

175. Powers, J.H. Editorial Commentary: Asking the Right Questions: Morbidity, Mortality, and Measuring What's Important in Unbiased Evaluations of Antimicrobials. Clin. Infect. Dis. 2012, 54, 1710-1713. [CrossRef]

176. Burkhardt, O.; Rauch, K.; Kaever, V.; Hadem, J.; Kielstein, J.T.; Welte, T. Tigecycline possibly underdosed for the treatment of pneumonia: A pharmacokinetic viewpoint. Int. J. Antimicrob. Agents 2009, 34, 101-102. [CrossRef]

177. Briggs, G.G.; Freeman, R.K.; Yaffe, S.J. Drugs in Pregnancy and Lactation: A Reference Guide to Fetal and Neonatal Risk, 9th ed.; Lippincott Williams \& Wilkins: Philadelphia, PA, USA, 2011; ISBN 978-1-60831-708-0.

178. Zimmerman, J.J.; Raible, D.G.; Harper, D.M.; Matschke, K.; Speth, J.L. Evaluation of a Potential Tigecycline-Warfarin Drug Interac. Pharmacother. J. Hum. Pharmacol. Drug Ther. 2008, 28, 895-905. [CrossRef]

179. Zhanel, G.G.; Siemens, S.; Slayter, K.; Mandell, L. Antibiotic and Oral Contraceptive Drug Interactions: Is There a Need for Concern? Can. J. Infect. Dis. 1999, 10, 429-433. [CrossRef]

180. Sriram, D.; Yogeeswari, P.; Senchani, G.; Banerjee, D. Newer tetracycline derivatives: Synthesis, anti-HIV, antimycobacterial activities and inhibition of HIV-1 integrase. Bioorg. Med. Chem. Lett. 2007, 17, 2372-2375. [CrossRef]

181. Castro, W.; Navarro, M.; Biot, C. Medicinal potential of ciprofloxacin and its derivatives. Futur. Med. Chem. 2013, 5, 81-96. [CrossRef]

182. Sun, C.; Hunt, D.K.; Chen, C.-L.; Deng, Y.; He, M.; Clark, R.B.; Fyfe, C.; Grossman, T.H.; Sutcliffe, J.A.; Xiao, X.-Y. Design, Synthesis, and Biological Evaluation of Hexacyclic Tetracyclines as Potent, Broad Spectrum Antibacterial Agents. J. Med. Chem. 2015, 58, 4703-4712. [CrossRef]

183. Tetraphase. Pipeline. Available online: https://www.tphase.com/products/pipeline/ (accessed on 6 October 2021).

184. PubChem TP-271. Available online: https:/ / pubchem.ncbi.nlm.nih.gov/compound/54726193 (accessed on 24 October 2021).

185. Grossman, T.H.; Fyfe, C.; O’Brien, W.; Hackel, M.; Minyard, M.B.; Waites, K.B.; Dubois, J.; Murphy, T.M.; Slee, A.M.; Weiss, W.J.; et al. Fluorocycline TP-271 Is Potent against Complicated Community-Acquired Bacterial Pneumonia Pathogens. mSphere 2017, 2, e00004-17. [CrossRef] [PubMed]

186. Sun, C.; Deng, Y.; Hunt, D.; Fyfe, C.; Kerstein, K.; Xiao, X. TP-6076, A Fully Synthetic Tetracycline Antibacterial Agent, Is Highly Potent against a Broad Range of Pathogens, Including Carbapenem-Resistant Enterobacteriaceae; ASM Microbe: New Orleans, LA, USA, 2017.

187. Liu, F.; Myers, A.G. Development of a platform for the discovery and practical synthesis of new tetracycline antibiotics. Curr. Opin. Chem. Biol. 2016, 32, 48-57. [CrossRef]

188. Grossman, T.; Hunt, D.; Iii, H.H.; Sutcliffe, J. TP-271, a Novel Oral Fluorocycline for Community-Acquired Respiratory and Biothreat Pathogens. In Proceedings of the 50th Annual Interscience Conference of Antimicrobial Agents and Chemotherapy, Boston, MA, USA, 12-15 September 2010; p. 1. 
189. Seifert, H.; Stefanik, D.; Olesky, M.; Higgins, P.G. In vitro activity of the novel fluorocycline TP-6076 against carbapenem-resistant Acinetobacter baumannii. Int. J. Antimicrob. Agents 2019, 55, 105829. [CrossRef]

190. Tetraphase Pharmaceuticals, Inc. A Phase 1, Open-Label, Randomized, PK and Safety Study to Assess Bronchopulmonary Disposition of Intravenous TP-6076 in Healthy Men and Women; ClinicalTrials.gov. Available online: https:/ / clinicaltrials.gov/ ct2/show/NCT03691584 (accessed on 28 November 2021). 